Illinois State University

ISU ReD: Research and eData

Theses and Dissertations

$4-14-2014$

\title{
My One Week, Two Month, Three Year Stand: Identifying The Sexual Script Of The Booty Call Relationship
}

Kayla Marie Lucht

Illinois State University, kmlucht@ilstu.edu

Follow this and additional works at: https://ir.library.illinoisstate.edu/etd

Part of the Communication Commons

\section{Recommended Citation}

Lucht, Kayla Marie, "My One Week, Two Month, Three Year Stand: Identifying The Sexual Script Of The Booty Call Relationship" (2014). Theses and Dissertations. 178.

https://ir.library.illinoisstate.edu/etd/178

This Thesis is brought to you for free and open access by ISU ReD: Research and eData. It has been accepted for inclusion in Theses and Dissertations by an authorized administrator of ISU ReD: Research and eData. For more information, please contact ISUReD@ilstu.edu. 


\section{MY ONE WEEK, TWO MONTH, THREE YEAR STAND: \\ IDENTIFYING THE SEXUAL SCRIPT OF \\ THE BOOTY CALL RELATIONSHIP}

121 pages

Kayla Marie Lucht

Growing evidence suggests that the booty call relationship is becoming more prevalent on college campuses. The primary objective of this study is to achieve a deeper understanding through in-depth respondent interviews about the sexual script of the booty call relationship, specifically, to inquire about the development, maintenance, and termination phases of the booty call relationship. A secondary objective is to reach better and more holistic understanding about the role that alcohol, text messages, and emotions play in the booty call relationship. Thematic analysis indicated a general script of the relationship; nuances in how booty call relationships evolve. Specifically, two factors were salient in these relationships: Alcohol played an important role in the development and maintenance phases; text messages played a substantial role in the development and termination phases. Finally, happiness and guilt were the two most reported emotions experienced while in the booty call relationship. 
MY ONE WEEK, TWO MONTH, THREE YEAR STAND:

IDENTIFYING THE SEXUAL SCRIPT OF

THE BOOTY CALL RELATIONSHIP

KAYLA MARIE LUCHT

A Thesis Submitted in Partial

Fulfillment of the Requirements

for the Degree of

MASTER OF ARTS

Department of Communication

ILLINOIS STATE UNIVERSITY

2014 
MY ONE WEEK, TWO MONTH, THREE YEAR STAND:

IDENTIFYING THE SEXUAL SCRIPT OF

THE BOOTY CALL RELATIONSHIP

KAYLA MARIE LUCHT

COMMITTEE MEMBERS:

John R. Baldwin, Chair

Sandra M. Metts

William R Cupach 


\section{ACKNOWLEDGMENTS}

I wish to thank many individuals as contributors to my graduate school career and Master's Thesis. Firstly, special thanks must be extended to my wonderful committee members, Dr. Sandra M. Metts and Dr. William R. Cupach, for providing helpful feedback and offering constructive suggestions in accordance with this research.

A sincere and special thanks is extended to my chair, Dr. John R. Baldwin. I hope he realizes the impact he has had, not only upon my thesis, but as well, my experience as a graduate student and graduate instructor, and on my overall self-confidence as a researcher. Thank you so much.

Next, I want to thank all 20 interviewees for their selfless volunteerism. These individuals took time out of their personal lives to sit down with me and self disclose very personal information that helps with my research. Without their help, this research would simply not be attainable. I would also like to thank my friends and colleagues, as they helped spread the word about my research.

I want to thank Rich Murphy, my favorite professor from Wayne State College. If it were not for his encouragement (and peer pressure!), I would not have even considered graduate school. Before I was even on board with the graduate school idea, he made sure I was prepared for my future by having me 
conduct research and presenting it at conferences. I owe him a lifetime of gratitude of directing me to the right path and for letting me vent whenever graduate school became overwhelming.

Finally, I wish to thank my family and best friends, for sticking with me as I completed graduate school. You were always there to keep me in line and made sure I was not wasting my day by binge watching SVU and napping. For the numerous and dramatic times that I thought everything was falling apart, you were always there (with wine in hand) to make sure I realized that everything would be okay. Love you all. 


\section{CONTENTS}

\section{Page}

ACKNOWLEDGMENTS

CONTENTS

CHAPTER

I. STATEMENT OF PROBLEM AND REVIEW OF LITERATURE

Statement of the Problem 1

Review of Literature $\quad 6$

Schemas, Scripts, and Dating Styles $\quad 6$

Schema theory 6

Traditional dating script 9

Sexual script theory 11

Changes in dating and sexual scripts $\quad 14$

Types of Non-Traditional Sexual Relationships $\quad 15$

Hooking up 17

One-night stands $\quad 19$

Friends with benefits 20

Booty calls 21

Factors that Influence Sexual Involvement 23

Alcohol 23

Telephone 25

Emotions Associated with Nontraditional

Sexual Relationships 25

$\begin{array}{ll}\text { Negative emotions } & 27\end{array}$

$\begin{array}{ll}\text { Anger } & 28\end{array}$ 
Jealousy

Regret

Sadness

31

Guilt

Embarrassment

Shame

Positive Emotions

Joy

Pride

36

Contentment

The Present Study

Conclusion

II. METHODS

Participants

Data Collection

Data Analysis

Conclusion

III. FINDINGS

The Booty Call Relationship 53

What is a Booty Call?

54

The Booty Call Experience

Elizabeth's story

56

Thomas's story

57

Kathy's story

60

Seth's story

The Sexual Encounter

Role

Props

Lines

68

Results

69

More Alcohol, Please 
Liquid Courage

Alcohol as an Excuse $\quad 72$

“Wanna Hang Out?”

$\begin{array}{ll}\text { Text Message } & 75\end{array}$

Texting throughout the different stages $\quad 75$

$\begin{array}{ll}\text { Sexting } & 77\end{array}$

$\begin{array}{ll}\text { Emotions } & 78\end{array}$

Excitement $\quad 78$

Happiness with Guilt $\quad 80$

$\begin{array}{ll}\text { Conclusion } & 83\end{array}$

$\begin{array}{ll}\text { IV. DISCUSSION } & 84\end{array}$

$\begin{array}{ll}\text { Additional Themes } & 85\end{array}$

Long-Distance Relationship $\quad 85$

I'm Just Not That Into You $\quad 87$

Not a good person $\quad 87$

Trust $\quad 88$

Setting The Script $\quad 89$

Alcohol, Text Messages, and Emotions 90

Alcohol $\quad 90$

Text messages $\quad 90$

Emotions $\quad 91$

Strengths, Limitations, and Directions for Future Research 93

Strengths and Limitations 93

Future Research $\quad 95$

$\begin{array}{ll}\text { Summary } & 98\end{array}$

$\begin{array}{lr}\text { REFERENCES } & 99\end{array}$

APPENDIX A: Email Message/Facebook Message To Prospective Participants 114 


\section{CHAPTER I}

\section{STATEMENT OF PROBLEM AND REVIEW OF LITERATURE}

\section{Statement of Problem}

In the song, Booty Call by Ke\$ha, the lyrics are explicitly about engaging in a booty call relationship and highlight the emerging hookup culture among young adults. Other songs such as Call Me by Too \$hort, Lying Is The Most Fun A Girl Can Have Without Taking Her Clothes off by Panic! At The Disco, and Senorita by Soulja Boy also have lyrics that are explicitly focused on the booty call relationship. It is not only music that emphasizes the hookup culture; magazines (Cosmopolitan, Glamour), books (Summer Boys by Hailely Abbot, Booty Call by Erick Gray, The Booty Call by Sha Jackson), television shows (How I Met Your Mother, Girl Code, The Secret Life of the American Teenager, Guy Code), and movies (No Strings Attached, Friends with Benefits, Booty Call) all place a significant focus on the sexuality of men and women. Research has shown that media serves as the primary foundation for young adults to understand, learn, and form opinions about the hookup culture (Garcia, Reiber, Massey, \& Merriwether, 2012). The media also portray alcohol and computermediated communication (e.g., text messages, emails, phone calls, social media) as factors for the initiation and maintenance of the hookup culture. 
Media also portray the unreciprocated positive and negative emotions developed by one individual for his or her casual sexual partner as the reason hookups are terminated (Chia \& Gunther, 2008).

Many different types of non-traditional sexual relationships are becoming the focus of research in the area of sexual communication. A strong case can be made for the fact that these relationships have become culturally normative among men and women throughout the American culture. Dating behavior outside of the traditional committed relationship has become significantly popular among young adults. Reiber and Garcia (2010) found that $81 \%$ of undergraduate students have engaged in some form of hookup behavior.

Sex communication scholars argue over the definitions of various types of non-traditional consensual sexual relationships such as, hookups, one-night stands, friends with benefits, and booty calls. Many of these relationships have similar characteristics, such as they are all sexual and consensual in nature; however, each non-traditional sexual relationship also has characteristics that differentiate it from the others.

The booty call relationship is understudied when compared to the other types of non-traditional consensual relationships in which young adults are engaging. Jonason, Li, and Cason (2009) define the booty call relationship as "the solicitation of a non-long term partner for explicit or implicit intent of engaging in sexual activity" (p. 460). They found that only $30 \%$ of college students reported that they have been in a booty call relationship. Since booty call relationships are under-researched, this study will focus specifically on the 
heterosexual booty call relationship rather than other non-traditional consensual relationships (i.e., one night stands, friends with benefits). Individuals would not know how to engage in any type of relationship without the use of scripts. Scripts are beneficial when it comes to attempting to predict another individual, present or future behavior as well as explain past behavior. Scripts are especially important to study when looking at the development of any non-traditional sexual relationship. Individuals use dating scripts and sexual scripts as a set of rules that they should follow to help reduce uncertainty within their relationships (Mongeau, Jacobsen, \& Donnerstein, 2007). Sexual scripts help individuals understand sexual encounters and also how to handle sexual experiences. Sexual scripts refer to the "cognitive models used in choosing and evaluating behavior in sexual context," such as flirting, dating, and sexual encounters (Simon \& Gagnon, 1986, p. 100).

In the last 60 years, the traditional dating and sexual script has significantly changed (Laner \& Ventrone, 2000). As young adults are developing more sexually permissive attitudes, dating for courting purposes has decreased (but not disappeared) and sexual behavior outside of the traditional romantic relationship has become increasingly acceptable (Bogle, 2007, 2008). It is no longer unusual for the woman to ask the man out on a date or for the woman to pay for the date (Masters, Casey, Wells, \& Morrison, 2013). It is also more ambiguous as to where the relationship stands after a few dates. Currently, women are seen as more sexually liberal than they have been in the past, 
which leads to the traditional gender norms about women and sexual activity only in a committed dating relationship being less strict (Banker, Kaestle, \& Allen, 2010; Laner \& Ventrone, 2000; Reiber \& Garcia, 2010). The shift from traditional dating scripts was influenced by women who decided to confront traditional gender roles and decided to have their needs and wants fulfilled (Serewicz \& Gale, 2008).

The rules of dating are also more ambiguous than compared to 60 years ago (Mongeau et al., 2007). A "date" does not always mean going to dinner or to a movie, but rather individuals are coming up with more relaxed and creative date ideas, such as meeting at a coffee shop, going to an outdoor concert, or just hanging out at a mutual friend's house (Epstein, Marina, Calzo, Smiler, \& Ward, 2009). More importantly, premarital sex is very common after just a few dates (Bogle, 2008; Jackson, Kleiner, Geist, \& Cebulko, 2011). By the age of $18,58 \%$ of Americans have already engaged in premarital sex, and by the age of 20, the number increases to $75 \%$ (Filner, 2007). As noted earlier, young adults are raised in an environment that heavily focuses on sex; therefore, by the time these young adults reach college, the concept of "casual sex" is nothing new.

There is limited research on the script for booty call relationships. This is unfortunate because these casual sexual consensual relationships may have implications for young adults' ability to form stable romantic relationships (Amato et al., 2008). The stability and termination of sexual relationships in young adulthood can affect psychological well-being and shape attitudes, 
values, and beliefs about romantic relationships (Collins \& van Dulmen, 2006; Raley, Criseey, \& Muller, 2007). Although Owen et al. (2010) found that for some young people hookups can provide a positive experience and improve psychological well being, it is only for a short time period. Therefore, the patterns of behavior learned in booty call relationships may thwart the development of commitment in healthy romantic relationships.

The primary objective of this study is to achieve a deeper understanding through in-depth interviews about the scripts that lead to the development, maintenance, and termination of non-traditional sexual relationships, specifically the booty call relationship. A secondary objective is to reach a better understanding about the role participants perceive alcohol, technology, and emotion to play in the development, maintenance and termination of the booty call relationship and scripts.

Pervasive in American culture is the tendency for college students to consume a large quantity of alcohol before engaging in sexual behavior. Garcia and Reiber (2008) found that $33 \%$ of individuals who engaged in an uncommitted sexual encounter was influenced by alcohol and drugs, which made the encounter unintentional. Furthermore, Fielder and Carey (2010) found that $64 \%$ of uncommitted sexual encounters were influenced by the use of alcohol. Alcohol may be used as a justification as to why individuals engage in casual sexual encounters (Paul, 2006). In addition, if individuals feel poorly about their decisions, they may attribute their behavior to alcohol and 
therefore keep their hookup a secret (Fisher, Worth, Garcia, \& Meredith, 2012).

Mobile phones have become one of the most universal interpersonal media, especially for young adults (Borae \& Pena, 2010). To initiate hookups, young adults are utilizing text messages as their primary source of communication (Lenhart, 2010). Also, these young adults choose to text for a variety of reasons which include flirting, starting and ending relationships, and facilitating social gatherings (Lenhart, 2010; Srivastava, 2005). Overall, with the influence of alcohol and text messages to initiate casual sexual relationships, booty call relationships could be much more popular than research suggests.

\section{Review of Literature}

\section{Schemas, Scripts, and Dating Styles}

Schema theory. Individuals use schemas to understand and organize knowledge. "Schema theory suggests that people are active processors of information and that schematic thinking derives from the need to organize thinking for the purpose of cognitive economy" (Wicks, 1992, p. 119). In other words, schema theory states that social knowledge is organized into units. Nishida (2005) states that an individual's behavior is connected to memories of experience stored within the brain, and that a given behavior relies on the person's past experience. This unit of knowledge, also known as a schema, determines how the person will react to the situation. A schema, then, is a generalized description or conceptual system for understanding knowledge and 
how it is interpreted and used (Miller, 2005). According to schema theory, schemas represent knowledge about concepts, such as objects and the relationship shared with other objects, situations, events, or actions. With each new experience an individual has, he or she will incorporate more information into his or her schema (Baldwin, 1992).

Four types of schema frames can help individuals understand different situations that they encounter. First, a person schema is defined as the understanding of the psychology of specific individuals. As Baldwin (1992) explains "individuals are assumed to view the world through the filter of their person schemas" and how this may include "expectations about what attributes of personality typically co-occur in other people" (p. 462). Person schemas help individuals interpret ambiguous information in a way that is consistent with their expectation, and to fill in gaps of information.

A second type of schema is the self-schema, which is the understanding about one's own behavioral tendencies. Markus (1977) found that when "an individual has a firm idea about their self in some domain of behavior, domain relevant information about the self is processed efficiently, confidently, and consistently" (p. 66). For example, if a person thinks, "I'm an introvert," that individual is going to process information and behave differently than if she or he has a different personal schema.

A third type of schema is the role-schema, which is an understanding of the appropriate norms and behaviors in social categories. These social categories can include, but are not limited to, age, race, sex, and economic 
status. An example of this would be "How teachers should act in the classroom." Finally, the event-schema is defined as the understanding of the typical sequences of events in a standard social occasion (Baldwin, 1992; Fletcher, 1993; Miller, 2005). An example of this would be "When you first meet an individual, you don't self disclosure a lot of personal information."

A schema is developed whenever an individual experiences a new situation. This new schema will be activated along with schemas that have been already developed, especially when the new schema is similar to the old schema (Koerner, 2009). Individuals who have well-developed schemas will be able to apply more schemas to unfamiliar situations. Schemas are dynamic and change as new information and experiences are processed and integrated. Wicks (1992) developed three models explaining how schemas change. First, with the bookkeeping model, changes are gradually made to schemas when information seems to be missing. Second, the conversion model is when missing information is discovered and completely changes the already developed schema. Finally, the subtyping model is when subcategories are used to change the overall schema.

Even though individuals have a schema on how they believe relationships should develop, there has not been any research on how schema theory applies to the development of non-traditional sexual relationships. How individuals understand and make sense of non-traditional sexual relationships will depend on the schema frame they use. 
Overall, each type of schema frame could have a different effect on how an individual understands and behaves in a non-traditional sexual relationship. Also, the different types of schemas could play a significant role in how the sexual script is developed for the booty call relationship.

Traditional dating script. Honeycutt and Catrill (2000) explain that "a script comprises a set of sequential step-by-step instructions for accomplishing a specific task," which refers to "the sequencing and categorization of behaviors across time to accomplish a goal" (p. 18). In other words, scripts are used to help individuals by giving guidelines on how to act when entering a new situation or simply enacting a routine episode.

According to Laner and Ventrone (2000), scripts are types of schema that allow an individual to organize his or her experiences. These scripts allow individuals to predict other individuals and also serve as guidelines for decisions on how to act. People accommodate their social responses in order to maximize their control over any given situation. This requires each individual to imagine a script for any past, present, and future behavior (Rose \& Frieze, 1993).

Conventional events have a scripted interaction with a specific sequence of both verbal and nonverbal communication (Metts, In Press). For example, a specific script guides how individuals say "goodbye" on the telephone. Usually one individual makes a face-saving statement such as, "It was so nice to talk to you" or, "Well I have to go, but I'll talk to you soon!" before she or he actually says "goodbye." The statement of these verbal messages signals that the 
conversation is coming to an end, and the knowledge of what typically happens in such occasions is evidence that there is a script.

Dating scripts provide many benefits within a romantic relationship. First, they allow individuals to reduce their uncertainty when they are in an unfamiliar encounter. Second, dating scripts expand an individual's sense of security by providing familiar patterns of behaviors for the situation (Duck, West, \& Acitelli, 1997). Like any script, dating scripts are developed through an individual's social experiences and interactions. These scripts can be changed or further developed not only based on their personal experience, but also by observing others' behaviors in similar situations. Honeycutt and Cantrill (2000) state, "Scripts occur in context and reflect the customs and values of both society and subculture in which they occur" (p. 24).

In a study considering the typical dating script for a first date between heterosexual couples, Pryor and Merluzzi (1985) found this sequence of behaviors (p. 369):

1) The man goes to woman's place of residence

2) The women greets him in a friendly manner

3) The man meets the individual she lives with

4) They engage in small talk and decide where to go

5) After the date, the man takes the women back to her place of residence

6) They exchange their feelings about the tonight, usually in a pleasant manner

7) They kiss good night 
8) The man leaves and goes to his place of residence

Dating expectations are strongly linked to the traditional dating script. In the traditional dating script, men are portrayed as active and interested in sexual intercourse, and they are characterized as the initiator of dates or any sexual activities. Also within in this script, men are encouraged to overcome any resistance from women about the advances they initiate (Gilbert, Clark, \& Anderson, 2012). In contrast, women are characterized as the emotional initiators and are highly interested in relationship development and maintenance. From this stereotyped characterization, women are supposed to be passive and less interested in sexual activities; therefore, they respond with hesitancy to the male's advances (Metts, In Press).

Other research has shown that in traditional dating scripts women expect the man to make the arrangements for the first date (Rose \& Frieze, 1993). Not only do women believe it is the man's duty to arrange the first date, but it is also the man's responsibility to pay for the date and to make any sexual moves (Laner \& Ventrone, 2000; Rose \& Frieze, 1993). Overall, dating scripts are important to help individuals understand and organize their experiences and social encounters. The dating script also helps individuals reduce uncertainty about others, and to better predict what will happen in a specific situation.

Sexual script theory. Sexual script theory describes how "cognitive models are used in choosing and evaluating behavior in sexual context," (Gilbert et al., 2012, p. 100) such as flirting, dating, and sexual encounters 
(Metts \& Spitzberg, 1996). Sexuality is learned from messages that create these scripts for what is considered as "sex," how to recognize and handle sexual situations, and what to do in sexual encounters (Simon \& Gagnon, 1986; Suvivuo, Tossavainen, \& Kontula, 2010). These sexual scripts operate on three different levels: cultural, interpersonal, and intrapsychic. As explained by Klinkberg and Rose (1994):

Cultural scripts are shared, collective guides that instruct members of appropriate behaviors and emotions of specific roles. The use of a cultural script in a specific situation constitutes an interpersonal script. Interpersonal scripts combine the actions present in cultural scripts with ones individuals typically add through experience. As a result, interpersonal scripts are more detailed and individualized than cultural ones. Intrapsychic scripts are those that represent our private wishes and desires. (p. 24)

In short, interpersonal level scripts are emergent and negotiated enactments of the cultural level script as modified by the blending of two intrapsychic level scripts (Metts, In Press).

According to Simon and Gagnon (1986), sexual scripts can vary during the individual's lifetime, but mainly these scripts are developed during the formative years of adolescences and young adulthood. Gender roles, stereotrypically, suggest that the male role takes possession of the object of desire, while the female role is the object of desire (Green \& Sandos, 1983; Mitchell et al., 2011). Research has shown that even today these traditional 
gender roles still have an impact on dating and sexual scripts. Even though it is not unusual for women to ask men out on a date, it can still be viewed as a violation of gender roles, which may result in negative outcomes (Backstrom, Armstrong, \& Puentes, 2012).

In the past, young women were seen as less sexually liberal compared to their male counterpart (Gilmartin, 2006; Laner \& Ventrone, 2000). Traditional gender norms encouraged women to see sexual activity as appropriate only when it occurred within the context of an emotionally committed relationship, that is, when sex was an expression of emotional intimacy (Serewicz \& Gale, 2008). These same traditional gender roles also taught women to repress their own sexual needs to please their male partner (Bowleg, Lucas, \& Tschann, 2004; Hynie, Lyndon, Cote, \& Wiener, 1998). A woman's worth, status, and power were all lessened if she was perceived as being sexually experienced and active, whereas a male's social status was increased by numerous sexual encounters (France, 2010).

Recent research indicates that there has been a shift in the traditional sexual script, especially in the American culture. Specifically, women have confronted the issues of having their own needs and wants fulfilled, which makes their pleasure become a more salient component in the sexual script (Suvivuo et al., 2010). Young women are becoming more sexually active than in the past and are starting to report a significant increase in the number of sexual partners they have before marriage (Suvivuo et al., 2010) 
Changes in dating and sexual scripts. Before the days of cell phones and social media, dating was seen as a simple affair that revolved around welldefined social norms. These past dating rituals indicated the proper way for men to court women, with marriage being the desired outcome. If men and women did not uphold these dating rituals, they were considered societal outcasts (France, 2010).

In the past, because of socially structured gender differences, such as men holding the steady job, men would be the ones who paid for the bill on the date and planned the elaborate romantic date to win the woman's affection. After a few dates, the couple would declare their exclusivity by "going steady." Then after a few years going steady, the couple would become engaged (France, 2010; LaPlante, McCormick, \& Brannigan, 1980)

In the past, when a couple was exclusive, it meant that men were not allowed to date other women; however, at the time social expectations allowed men to have sexual intercourse with any woman who was willing. On the contrary, women were expected to remain virgins until they were married and if a woman broke this rule then she would be seen as promiscuous and undesirable (LaPlante et al., 1980; Morr \& Mongeau, 2004).

Today, the rules of dating are more ambiguous. A date does not always mean going to dinner or a movie, but rather there are more creative dates being used. It is still common for the men to initiate the date, but it is no longer looked down upon if a woman initiates the date (Laner \& Ventrone, 2000). 
Not only is premarital sex more common, but also casual sex is a more frequent theme among young adults. In America, young adults today are raised in an environment that is heavily focused on sex; therefore, by the time they are young adults the concept of "casual sex" is nothing new. On college campuses, casual sex tends to be just as popular as traditional dating (Gute \& Eshbaugh, 2008). When casual sex is defined as vaginal, oral, or anal sex with a person with whom one is not in a committed relationship, $52 \%$ of male students and $36 \%$ of female students report participating in these types of sexual behaviors (Grello, Wesh, \& Harper, 2006).

\section{Types of Non-Traditional Sexual Relationships}

Heterosexual dating in the American culture has taken two primary forms, which are traditional dating and "getting together" (Coleman, 1988). Traditional dating is more gendered and formal between the two individuals. As stated earlier, the traditional script includes the man making the arrangements, paying for dinner, and making any sexual moves (Jackson et al., 2011).

However, the other dating form is "getting together," which is more informal compared to traditional dating. This type of dating style is "less overtly tied to exploitive gender roles" (Jackson et al., 2011, p. 632). This involves meeting in informal places and with more people, such as getting coffee with a group of friends, playing games, or just hanging out. These group activities are preliminary meeting places for people who are attracted to each 
other and want to become better acquainted before making the decision to go on a formal date (Coleman, 1988).

Within the context of getting together is the formation of the casual sexual relationship. This type of relationship is distinguished by a lack of commitment and fewer nonsexual encounters than exclusive relationships (Jackson et al., 2011). Thus, hooking up has become an alternative label for casual dating. Paul et al. (2002) define a hook up as "a sexual encounter, usually lasting only one night, between two people who are strangers or brief acquaintances" (p. 76). However, the scholars argue that not all hookups will result in sexual intercourse. College campuses are well known for the development of sexual permissiveness among students (Chng \& Moore, 1994). Research shows that approximately $50 \%$ of students engaged in casual sexual relationships within the past year (Owen, Rhoades, Stanley, \& Fincham, 2010), while $77 \%$ of sexually active middle adolescents and $85 \%$ of sexually active late adolescents reported any casual sexual relationship (Grello, Welsh, Harper, \& Dickson, 2003; Sandberg-Thomas \& Kamp-Dush, 2014).

Even though research has shown a high frequency of hookups within the college campus setting, hookups have also been occurring among younger teenagers. Research shows that around $60 \%$ of sexually active teenagers have had sex with an individual with whom they are not in a traditional dating relationship (Manning, Longmore, \& Giorando, 2000).

With the rising rate of casual sex encounters on college campuses, it is vital to understand the most common types of casual sexual relationships. 
There are various types of non-traditional sexual relationships that include casual sex. All of these relationships are distinct, yet they share similar traits and can easily be confused. Casual sex relationships can vary by the degree of sexual activity, motivation for individuals, and whether the relationship develops into a traditional sexually exclusive relationship (Paul, Wenzel, \& Harvey, 2008).

These relationships are both motivated by short-term and long-term factors. For short-term factors, both men and women usually place physical attractiveness as a major priority when engaging in a casual sexual encounter. For the long-term factors of engaging in a casual sexual encounter, both men and women enjoy the repeated sexual interactions (Jonason et al., 2009). These non-traditional sexual relationships are appealing for both men and women, but for different reasons. For men, having a relationship with lowinvestment and high sexual satisfaction motivates them to be in a nontraditional sexual relationship (Buss \& Schmitt, 1993; Li \& Kenrick, 2006; Townsend, Kline, \& Wasserman, 1995). However, for women the repeated interactions give them a "trial run" to assess the potential for a committed long-term relationship (Impett \& Peplau, 2003; Li \& Kenrick, 2006). Research outlines several different types of uncommitted sexual relationships.

Hooking up. Individuals use the word "hookup" to mean a variety of behaviors, such as, kissing to oral intercourse to having sex with a stranger, friend, and/or significant other. Since the word hook up is used so diversely and interchangeably among individuals, researchers cannot agree on a set 
definition of "hookups." According to Garcia et al. (2012), hookups are characterized as a form of casual sex or an uncommitted sexual encounter. However, Hatfield, Hutchinson, Bensman, Young, and Rapson (In Press) define hooking up as a sexual encounter that occurs outside the formal traditional dating relationship and without a traditional purpose (i.e. procreating, in love). On the other hand, Paul et al. (2000) define a hook up as "a sexual encounter, usually only lasting one night, between two people who are strangers or brief acquaintances. Some physical interaction is typical but may or may not include sexual intercourse" (p. 79). Furthermore, Garcia and Reiber (2008) define a hook up as "a sexual encounter between people who are not dating or in a relationship, and where a more traditional romantic relationship is not an explicit condition of the encounter" (p. 196). For the purpose of this study, I will define hookups as "casual sex that occurs outside a traditional romantic relationship context and without the explicit expectation of forming a relationship” (Glenn \& Marquardt, 2001, p. 13).

Hooking up has become more popular over the past 60 years. The traditional dating schema of courtship and pursuing a romantic relationship has shifted to more of a casual hook up culture (Bogle, 2008). In recent years, the idea of "hooking up" has become more socially acceptable, thus making it more culturally normative. Research has indicated that undergraduate college students of both sexes have nearly doubled the number of hookups compared to first dates (Bradshaw, Kahn, \& Saville, 2010). What is interesting about this 
research area is it that both sexes are willing to openly discuss their experiences of hooking up (Garcia et al., 2012).

One-night stands. A one-night stand is defined as "a sexual encounter, which may or may not include sexual intercourse, usually occurring between people who are strangers or brief acquaintances” (Paul, McManus, \& Hayes, 2000 , p. 76). Just as the name implies, this sexual encounter is never repeated. It should be noted that Paul et al. use very similar definitions for hook up and one-night stands. While both of these casual sexual encounters share similar characteristics, they are different.

One-night stands are seen as a convenient and uncomplicated way of attaining sexual satisfaction with a stranger or acquaintance and without the limitations of interdependence, commitment, and exclusivity (Campbell, 2008; Sprecher \& Metts, 2013). Within the one-night stand, the two strangers or acquaintances have no expectations of having future connections or developing an exclusive committed relationship. Consuming alcohol, partying, and dancing are large contributors to the initiation of one-night stands. In terms of the onenight stand, research has found that more men than women have a more positive attitude towards casual sex with multiple partners (Campbell, 2008; Oliver \& Hyde, 1993).

As noted above, hookups are a type of casual sexual encounters that occur outside a relational context, but hook up partners often share social networks or frequent the same entertainment venues, thus meaning they can 
happen more than once (Eshbaugh \& Gute, 2008; Manning et al., 2006;

Townsend \& Wasserman, 2011; Wentland \& Reissing, 2011).

Friends with benefits. Another type of non-traditional relationship is the friends with benefits relationship, which has recently received much attention from interpersonal researchers. Just as the name implies, this relationship emerges when partners in a preexisting friendship decide to add the component of repeated sexual encounters.

The friends-with benefits relationship shares similar characteristics and aspects of both traditional friendships and romantic relationships (Owen \& Fincham, 2012). The individual in a friends with benefits relationship has the normal components of a friendship such as shared activities, mutual friends, and trust. However, it also has one component of a traditional dating relationship and that is, sexual intimacy. The addition of sexual intimacy increases the perceived quality of the friendship but does not make it a romantic relationship (Afifi \& Faulkner, 2000).

Research suggests there are two prominent reasons that young adults enter a friends with benefits relationship. The first is that some young adults use friends with benefits to receive sexual satisfaction with a person with whom they already have a strong friendship, thus leading the individuals to feel more comfortable within the non-traditional sexual relationship (Owen \& Fincham, 2012). The second reason is that many young individuals perceive a friends with benefits relationship as a new and exciting way to explore a possible romantic relationship. Some young adults use friends with benefits as a 
"trial run" to see if their partner would make a potential significant other in the future (Furman \& Shaffer, 2011; Owen \& Fincham, 2012). Owen and Fincham (2011) found that about $25 \%$ of men and $40 \%$ of women in friends with benefits relationships had high hopes that their relationship would progress into a committed and exclusive relationship. However, Bisson and Levine (2009) found that only $10 \%$ to $20 \%$ of friends with benefits relationships actually progress into a committed exclusive relationship.

The friends with benefits dating script is much less formal and more ambiguous than the traditional dating script, which makes it difficult to interpret the emotions and affective states one or both of the individuals are experiencing from the relationship (Bogle, 2007). Young adults typically describe their friends with benefits relationships as more positive than negative, due to the fact that this relationship is with a trusted friend; however, it is interesting to note that found that young adults who are in such relationship engage in more alcohol use and less effective decision-making (Owen \& Fincham, 2011). When the relationship is not kept at a positive current state for both partners, the relationship can start to diminish which can end in a complicated or terminated friendship (Bisson \& Levine, 2009).

Booty calls. As stated earlier, a booty call relationship is defined as "the solicitation of a non-long term partner for explicit or implicit intent of engaging in sexual activity" (Jonason et al., 2009, p. 460). In other words, it is a type of non-traditional sexual relationship that involves repeated sexual encounters, but there is no desire for the development of an exclusive 
romantic relationship. The booty call is a compromise relationship that has components from both traditional and non-traditional sexual relationships that both men and women are seeking. For males, the booty call relationship has low-cost investment, and for females the booty call relationship has the possibility of further commitment (Jonason et al., 2009).

Beyond other forms of non-traditional sexual relationships, booty call adds the component of computer mediated communication (CMC) and telephones. Where other types of non-traditional sexual relationship are usually developed in a face-to-face interaction, for example at a bar or other social gatherings, booty calls involve making contact when the two individuals are not close in proximity (Jonason et al., 2009). Usually this is done through a phone call or text message between the two individuals. Each message is brief and explicitly direct. For example, one individual, (usually the male) will text the female "U busy?" or "Wanna come over?" (Backstrom et al., 2012). Even though these messages do not directly state that sexual intercourse will happen, it is implied. This is due to the fact that this relationship is based on sexual gratification, and not developing a friendship or a romantic relationship.

A booty call relationship is often confused with the friends with benefits relationship and one night stand, when in reality a booty call relationship falls in the middle between these two non-traditional sexual relationships. The booty call relationship is similar to a one night stand because partners assume that no romantic relationship will develop. Yet it is also similar to a friends with benefits relationship because there are repeated sexual encounters with 
the same person. At the same time, the state of this relationship seems limited. Jonason et al. (2010) suggest that individuals in a booty call relationship will avoid using displays of emotional intimacy, such as kissing, cuddling, and hand holding and will leave promptly after sex as these tactics prevent the relationship from becoming an exclusive romantic relationship (Jonason et al., 2010).

The booty call relationship is significantly understudied when compared to the other types of non-traditional sexual relationships. As noted above, with the growing popularity of non-traditional sexual relationships on college campuses, research suggests that only $30 \%$ of college students report being in a booty call relationship (Jonason et al., 2009). However, booty call relationships may be more popular than research suggests.

\section{Factors that Influence Sexual Involvement}

A variety of influences are associated with an individual's decision to engage in a noncommittal casual sexual encounter. Research has found that risk-taking (Barriger \& Velez-Blasini, 2013), alcohol use (Cooper, 2002; Gold, Karmiloff-Smith, Skinner, \& Morton, 1992), technology (Jonason et al., 2009), and self-esteem (Gentzler, 2004; Weaver \& Herold, 2000) all influence the decision-making process to engage in a casual sexual encounter.

Alcohol. Research has shown that alcohol is strongly associated with the development and relational maintenance of casual sex relationships. Bersamin, Paschall, Saltz, and Zamboanga (2012) has found that high alcohol consumption was a predictive factor at all points in casual sexual encounters; they also 
found that the level of intoxication was its highest at the development of the sexual encounter. When the males and females had a brief acquaintance as their casual sexual partner, the level of intoxication was much higher than compared to if the male or female had a previous relationship with the partner (e.g., friendship) (Gold et al., 1992; Paul, et al., 2000). In more recent research, Garcia and Reiber (2008) found that 33\% of undergraduate students who reported being a non-traditional sexual relationship said that alcohol was an influence in their decision to engage in the sexual encounter. A similar study found that nearly $61 \%$ of undergraduate students consumed alcohol during their most recent hook up (Lewis, Granato, Blayney, Lostutter, \& Kilmer, 2011).

It is evident that casual sex encounters and alcohol intoxication are intertwined, but it is difficult to reach a conclusive understanding of the nature of this association. Research has shown that college students expect to use alcohol during an interaction that has potential to develop into a hookup, just so it will heighten the possibility of the actual sexual encounter (Vander Ven \& Beck, 2009). Consuming a significant amount of alcohol will make casual sex more likely to happen due to the disinhibiting effects of alcohol, but alcohol may also serve as an excuse or a strategy to justify the hook up behavior, either before or after the encounter (Vander Ven \& Beck, 2009).

Drinking alcohol gives the drinker 'beer goggles,' which decreases an individual's notion of other people's sexual attractiveness (Kalish \& Kimmel, 2011). Men, for example, use alcohol as a justification as to why women they are attempting to pursue repeatedly reject them. This also holds true for their 
sexual performance if they are able to find a consenting partner. For women, alcohol encourages them to be more forward and open in their sexuality. Also, women are able to use the excuse of alcohol to justify their sexual encounter if it results in negative emotions or their peers are scrutinizing them (Epstein et al., 2009; Kalish \& Kimmel, 2011; Paul, 2006).

Telephone. One aspect of the booty call relationship that is different from the aforementioned non-traditional sexual relationships is the use of telephones. Whereas one-night stands are initiated at a social event and friends with benefits have the pre-existing friendship, booty calls uniquely involve contact over telephone calls or text messages (Jonason et al., 2009). Research has shown that phone calls were more common than all other methods of communication to initiate a booty call (Jonason et al., 2009). The same research also found that men were more likely than women to make the phone call to initiate the booty call. However, with the rise of text messages and social media usage among young adults, it would be interesting to see if these two channels have become more popular than the telephone call in the solicitation of a booty call "hookup."

\section{Emotions Associated with Nontraditional Sexual Relationships}

Emotions are a type of affective state that are induced by internal or external stimuli. Emotions have a short-term arousal that produces coordinated changes in people's thoughts, actions, and physiological responses (Fredrickson \& Branigan, 2005). Emotions occur on a spectrum of valence, ranging from extremely positive to extremely negative, as well as a spectrum of potency, 
ranging from passive (sadness) to strong (anger). Furthermore, emotional experience refers to the intrapersonal, internal reaction an individual has to an emotion-eliciting stimulus (Barrett, 2006). Emotions arise when a person consciously or unconsciously evaluates a stimulus event as important to his or he own goals or well-being.

Emotion is one element within a larger concept known as an affective state. Affect refers broadly to any kind of diffuse arousal that might include personality traits such as shyness or long-term feeling states such as depression or grief (Knobloch \& Metts, 2013). Positive affect might include the experience of warmth, support, and acceptance and while negative affect might include the experience of hostility, stress, and rejection (Batson et al., 1992). Finally, emotions are distinguished according to their complexity and social influence. That is, small sets of emotions are considered basic or primary (i.e., anger, sadness, fear, disgust, and happiness). These innate emotions activate survival responses located in primal areas of the brain. Of course, appraisal processes modify the nature of expression based on evaluation of the circumstances that elicit the response. By contrast, most other emotions are secondary, blended, or social emotions, and include the complicated array of emotions such as envy, jealousy, hurt, guilt, embarrassment, shame, hope, pride, disappointment, forgiveness, and so forth. These emotions consist of blends of other emotions, for example, jealousy may include fear, guilt, love, and anger. Whether primary or secondary, emotions serve functions within society. Emotions are seen as essential to interpersonal functioning (Hayes \& Metts, 
2008). Emotions function to motivate individuals who are experiencing them to do something about those feelings - whether it is to eliminate the emotions if they are negative or sustain the emotions if they are positive. The next section will discuss the most prominent positive and negative emotions that are elicited through non-traditional sexual relationships.

Negative emotions. Negative emotions function as signals of danger and motivate the individual to respond accordingly to reduce the negative emotions (Roelofs et al., 2010). The appraisals of the primary event determine what type of negative emotion is experienced. Studies show that the negative emotions of anger, guilt, and sadness are often felt together (Fehr, Baldwin, Collins, Patterson, \& Benditt, 1999; Zisowitz, 1993).

Negative emotions are particularly important to understand in regards of non-traditional sexual relationships. When individuals develop a non-traditional sexual relationship, the relationship may elicit different emotions for men and women. At one time or another, people's feelings can get hurt, and jealousy, or even guilt can occur, which in turn can influence the relationship (Bevan \& Hale, 2006).

Therefore, it is important to understand the negative emotions that are most commonly experienced within a non-traditional sexual relationship. There have been many different negative emotions identified in the field of emotion research; the present study is focusing on the seven negative emotions that are most commonly felt within non-traditional sexual relationships. 
Anger. The emotion of anger occurs when an individual's goals are prevented in an unreasonable, dishonest, or unfair way. Anger also results when external factors block an individual's attempt to accomplish a goal or harm the individual. In other words, anger occurs when a goal has been thwarted and the situation can be analyzed in terms of the characteristics that have led to the thwarted goal (Rivers, Brackett, Kataulak, \& Salovey, 2007). Anger is aroused in individuals when the person feels that their self-esteem is being threatened, when they disagree on perceived incompatible goals, or when they believe that others do not appreciate them. However, anger can be seen in a positive light because it can help an individual maintain control and power in social situations (Fehr et al., 1999).

To reduce anger, one must be try to make right of the unjust situation, confront the harmer, or fight back. When an individual expresses anger, his or her facial features convey strength, dominance, and coldness (Knobloch \& Metts, 2013). There are different ways to express anger, which include withdrawing, avoiding the situation or behaving aggressively in a direct or indirect manner (Hayes \& Metts, 2008). Anger can also be expressed in prosocial ways, such as calmly discussing the situation, expressing feelings, or trying to negotiate a more desirable outcome (Knobloch \& Metts, 2013).

When an individual feels anger, it may or may not be expressed overtly. Anger-in is when an individual keeps his or her anger under stress and does not express the anger (Fehr et al. 1999). On the other hand, anger-out is either physically hitting or hurting objects or individuals, or using oral expression such 
as cursing, affronting, or criticizing. Anger control means having a general tendency of behaving in a patient, calm, tolerant, and understanding manner. Most importantly with anger control, individuals learn how to properly control their anger and calm down (Rivers et al., 2010).

Jealousy. The emotion of jealousy occurs when another individual who is perceived as a rival threatens an important or valued relationship, either a romantic relationship or a platonic relationship (Bevan \& Hale, 2006). Scholars have noted that jealousy involves a blend of emotions including anxiety, fear, insecurity, anger, sadness, envy, and guilt (Goa, Wang, \& Qian, 2010).

Jealousy is a threat to an individual's self-esteem and is usually expressed in either destructive or constructive ways (Tracy \& Robins, 2004). For example, the individual may either punish his or her partner or strive to build a stronger relationship. Research has found that responses to partner's jealousy include reassurances, ignoring, downplaying the jealousy, highlighting, denying, or trivializing attraction to the rival, and explaining the situation to the partner (Bevan \& Hale, 2006).

Bevan and Hale (2006) also outline three ways an individual can express jealousy. First, an individual can use integrative communication, which is direct and not aggressive expressions, including disclosures and encouragements. Second, negative affect expression can be used to express jealousy. This includes verbal statements of feeling jealous as well as nonverbal communicative expressions such as crying, ignoring, or appearing to have hurt feelings. Finally, people can use disruptive communication, which 
includes direct and aggressive verbal communication such as arguing, shouting, accusations, or sarcasm.

The emotion of jealousy can be good for a relationship, because it indirectly warns an individual when something could be wrong and helps him or her preserve the current state of the relationship. However, jealousy can be harmful if it is taken too far without the proper communication causing the individual to feel stressed and creating tension within the relationship.

Regret. The emotion of regret occurs when individuals blame themselves for a disastrous event that could have had a better outcome (Saffrey, Summerville, \& Roese, 2008). Regret is often a mix of sadness, shame, embarrassment, guilt, or hurt (Gilbert, 2003). Regret has been identified as a counterfactual emotion, which means that the basis of the emotion rests on how the past could have been done differently. Counterfactual thinking has been shown to have positive benefits in the aspects of problem-solving and making sense of a negative experience so it does not reoccur in the future (Saffrey et al., 2008).

Regret is a negative emotion that most individuals want to avoid; however, according to recent research, people actually attach value to their regretful experiences in two ways (Hayes \& Metts, 2008). First, they attach value in an absolute sense, which is where the favorable aspects counterbalance the unfavorable aspects. Second, individuals attach value in a relative sense, which is when they compare it to other negative emotions they have felt in the past (Saffrey et al., 2008). Regret has been found to be more 
favorable than other negative emotions, which could be attributed to the fact that other negative emotions serve different psychological functions such as sense making, insight, or social harmony (Saffrey et al., 2008).

If regret is experienced in a context where two individuals were involved, it is often verbally expressed through the form of apologizing. However, if regret happened in an intrapersonal context, an individual may express regret through feeling hurt, withdrawing from any social interactions, or avoiding the experience (Rodriquez, Fischer, Manstead, \& Antony, 2008). Whether regret happens in an interpersonal context or an intrapersonal context, an individual may ruminate about the negative experience and try to find a solution to make the negative situation a positive one, therefore reducing the negative arousal (Saffrey et al., 2008).

Sadness. Sadness is an emotion experienced during an event described as unpleasant. The emotion of sadness arises when something of importance is lost without a blameworthy target (Rivers et al., 2007). Sadness is considered a “me" emotion versus an "it" emotion. When people experience sadness, the focus is on the consequences of the loss to the self, as opposed to anger, for example where the focus is on the external cause of frustration (Zisowitz, 1993). Sadness can function as a form of constructive self-examination.

The bulk of research on sadness seems to indicate that sadness impairs attention to tasks by slowing cognition and motor systems (Tracy \& Robins, 2004). Sadness lowers attention because the focus is not on another agent, but on internalized pain. Sadness generally occurs in response to something that 
has already taken place. Individuals do not feel that they are at fault for the event and they feel as if no one is to blame (Rivers et al., 2007).

In American culture, sadness is associated with a kind of slowing of the body, a feeling of inactivity, and a sense of sluggishness or weakness.

Vocalizations of sadness are considered smaller, softer, and slower than those of anger (Zisowitz, 1993).

Guilt. Guilt is a negative, self-conscious emotion that requires selfawareness and self-representation. It is complex and serves primarily social and interpersonal needs as powerful motivational and regulatory forces in an individual's daily life (Goa et al., 2010) Guilt evolved from a primordial social system of caring and avoiding doing harm to others.

Individuals experience guilt when they focus on negative aspects of their behavior, such as "the thing done or undone" (Tracy \& Robins, 2004, p. 107). Guilt is elicited by internal attributions and results when unstable or uncontrollable behaviors or aspects of the self are blamed for unfortunate consequences.

Guilt is regarded as a moral emotion because it is outwardly focused and is about responsibility and caring feelings for others. In order to feel guilt, one must participate in the process of metacognition. Metacognition is "cognition about cognition" (p. 1207). In other words, this is the ability to reflect and judge one's own thoughts and feelings and also to organize them in an efficient manner (Gilbert, 2003). 
The role of the self is particularly important to understanding guilt. In guilt, the self is not the central object of negative evaluation but rather, the thing done or undone is the focus. In guilt, the self is negatively evaluated in connection with something but is not itself the focus of the experience (Gilbert, 2003). A person experiencing guilt focuses on a negative behavior, which is separate from the self. When focusing on the bad behavior, rather than a bad self, a person in the midst of a guilt experience is likely to recognize and to have concerns about the effects of her or his behavior on other individuals (Goa et al., 2010)

When guilt is felt, reparations can be offered, blame can acknowledged, and/or apologies can be expressed. Such actions are directed towards making amends to another person or group for some wrongful act, and are typically motivated by the core primary emotion of guilt, sadness (Gilbert, 2003).

Embarrassment. Embarrassment occurs when an action threatens the assumptions of a participant's projected identity and discredits one's interactional face (Goffman, 1956, 1967). Embarrassment, therefore, is "located not in the individual but in the social system" (Goffman, 1967, p. 108). Embarrassment results from events in which people lose control of a situation, which appears inconsistent, inappropriate, or incongruous to the people who have witnessed the event (Miller, 1996). Embarrassment is associated with confused behavior and the absence of poise and grace (Goffman, 1967). Embarrassment disrupts the smooth, predicable flow of social interactions. Due to the fact that embarrassment is acknowledged and recognized by others, 
embarrassment may have a substantial effect on the interactions in which it occurs.

Embarrassing predicaments encompass a wide range of events. There are five specific types of events that commonly cause embarrassment. These include impropriety, lack of competence, consciousness, breach of privacy, and being overpraised (Cupach \& Metts, 1992; Edelmann, 1985).

Embarrassment generally requires acknowledgement of an outside perspective. The bigger the audience, the stronger one's embarrassment is likely to be. Realizing that someone is embarrassed, other participants in the interaction may respond with compassionate support or hostile rejection, but only rarely do they fail to respond at all (Cupach \& Metts, 1992).

Shame. Many scholars describe shame and guilt as very similar emotions because they both involve one perceiving him or herself as the problem; however, these two emotions are distinct. Shame is the consequence of an individual's evaluation of an event that failed to meet his or her ethical and/or moral standards (Lewis, 1992). The emotion of shame is elicited when other individuals are aware of one's actions. When an individual experiences shame, the emotional response is to focus on the action or the self. Feelings of shame happen when a perceived negative action is viewed as destructive to the integrity of the self (Horan \& Dillow, 2009). Shame can also arouse other social emotions such as embarrassment, inadequacy, and self-contempt. Overall, when individuals experience shame, they tend to focus on themselves and not their actions or behaviors that caused them to feel this way (Lewis, 1992). 
Positive emotions. Individuals usually experience many more negative emotions compared to positive emotions. Negative emotions have been a primary focus in the emotion research world, due to the fact that negative emotions can have extreme and prolonged effects that can produce problems for individuals (Fredrickson \& Branigan, 2005). Also, there are more negative emotions than positive emotions because there are more kinds of threats than opportunities. Even though positive emotions are understudied, it is still very important to understand them.

Positive emotions are important for individuals to experience because after experiencing negative events, people use ego resilience. Ego resilience is defined as an individual's ability to adapt to changing environments, having opportunities, and bouncing back from a negative experience (Hareli \& Parkinson, 2008). When an individual experiences positive emotions, he or she will likely have a higher level of ego resilience, which will lead to many positive life outcomes. For example ego resilience is related to better interpersonal change, faster recovery after being ill, and less depression (Hareli \& Parkinson, 2008).

Joy. Joy is often used interchangeably with happiness and is similar to other positive affective states such as amusement, elation, and gladness (Fredrickson \& Branigan, 2005). Emotional theorists have defined joy as a strong positive emotion that is experienced in the context of obtaining progress toward a goal (Knobloch \& Metts, 2013). This goal can include a social success such as receiving affection or establishing intimacy. 
During the emotion of joy, the individual is motivated to move towards something, such as a goal, without fearing harm (Roseman, 2001). An individual will feel joy when a situation is appraised as safe and familiar. The emotion of joy creates the urge for individuals to play and to be playful.

Joy tends to be a relatively intense emotion with a long duration, thus leading to a high level of positive energy. This positive energy makes individuals share their good feelings through laughing, smiling, being talkative, hugging, and being enthusiastic (Fredrickson \& Branigan, 2005). Perhaps the most important consequence of happiness and joy is their effect on the person's ability to solve problems. According to the Broaden and Build Theory (Fredrickson \& Branigan, 2005), positive emotions broaden individual's momentary thought-action repertories, meaning they widen the array of thoughts and actions that come to mind (Fredrickson, 1998, 2001). The broaden mindset carries indirect and long-term benefits through building personal resources which can help manage future threats (Fredrickson, 2001).

Pride. Pride is a positive emotion that is experienced by an individual who positively evaluates his or her competence or effort in achieving a goal. It is also associated with self-achievement, autonomy, and release from others (Rodriguez et al., 2000). Pride will more likely be aroused in high-involvement events or decisions. When an individual achieves a goal, this "goal" must be valued for its uniqueness either subjectively or objectively (Zammuner, 1996). Unlike shame, which diminishes an individual's self-esteem, pride gives it a "boost" after a goal is accomplished. What is interesting about pride is that it 
is based on both self-appraisals and others' opinions about the goal that was achieved. If an individual feels large amounts of pride this can lead to egoism, arrogance, or excessive positive self-esteem (Zammuner, 1996).

Contentment. Contentment is an affective state that some scholars consider to be an emotion. It arises in situations that are seen as safe, having a high level of certainty and a low level of effort. Contentment is a positive emotion that is often used interchangeably with tranquility or serenity. This emotion has been seen to share aspects with mild joy and relief (Fredrickson \& Branigan, 2005).

When individuals first experience contentment, it is connected to no real action and it will have a "doing nothing" effect; however, scholars have taken a close look at contentment and realize that contentment sparks cognitive changes rather than physical changes. This emotion of contentment helps individuals appreciate their current life situations and thus leads them to be at ease with the surroundings, relationships, and the world as a whole. Contentment is a mindful emotion that involves full awareness of and openness to momentary experiences, which in turn forms a new and more positive sense of self (Fredrickson \& Branigan, 2005).

\section{Emotional Reactions to Casual Sexual Relationships}

Research indicates that females' emotional reactions to casual sexual encounters are more negative, whereas males' emotional reactions tend to be more positive (Hasleton \& Buss, 2001). Specifically, less sexually liberal women experienced more intense and prolonged emotional distress following the 
dissolution of a non-traditional sexual relationship than compared to sexually liberal women and men as a whole (Simpson, 1987). Townsend (1998) found that women expressed concern pertaining to quality and the duration of the relationship investment, even when the women were at complete acceptance with the casual sexual relationship. The various concerns about investment expressed by the women included wondering if the man would call, if he cared for her or just wanted sexual gratification, or if she would see him again.

Along with this, research found that for women, "not knowing their partner and the lack of contact with the partner seemed to compound their regret and anger at themselves”' (Paul \& Hayes, 2002, p. 655). After engaging in a casual sexual encounter, many women felt hurt and confused about their future relationship with that specific partner. Common negative themes for females include shame, regret, self-blame, and felt-pressure to engage in unwanted sex acts.

Men who reported having more casual sexual partners actually expressed fewer negative emotions, compared to women who had multiple sexual partners (Glenn \& Marquardt, 2001). Males have also reported more positive emotions being elicited after casual sex than females (Owen \& Fincham, 2011). Males experienced negative emotions more intensely, however, when they felt that their sexual partner was insufficiently attractive or that their sexual partner was too promiscuous (Paul et al., 2000). The experience of positive emotion may be based on the fact that men are more likely to be focused on sexual satisfaction rather than relationship satisfaction. Due to a lack of 
investment, men rarely felt regret or shame for engaging in casual sex. However, women did report positive emotions when they perceived the man to be investing in the relationship at a level the women found suitable, the women felt in control of the relationship, and feelings of worry, helplessness, and manipulation were not elicited (Townsend, 1998).

Research has shown that men have consistently expressed more comfort than women for engaging in casual sex (Cohen \& Shotland, 1996). Research has also shown that college men, compared to college women, would appear to benefit more from hooking up compared to a traditional date (Cohen \& Shotland). This is due to the small chance that rejection will occur, since intense flirting will happen promptly before the hookup.

Cohen and Shotland (1996) found that college women consistently express less comfort when they are engaging in sexual behaviors. There is a sexual double standard with women and casual sex, which can make women feel guilty about hooking up. This sexual double standard affects the perceptions of women by making them seem more promiscuous by other individuals than they really are (Bradshaw et al., 2010). However, females sometimes engage in non-traditional sexual relationships because they believe they are meeting their partner's needs and are providing comfort and satisfaction, which could possibly lead to an exclusive relationship (Impett \& Peplau, 2003). 


\section{The Present Study}

To date, only a handful of research studies have addressed the topic of booty call relationships. Even though the empirical knowledge of booty call relationships is growing, it is still limited. The present study explores individuals' personal experiences of booty call relationships and the various influences within the booty call relationship. Previous research is limited by an extensive self-report questionnaires and surveys, which does not help the researcher to find out the "why" that is behind the "what." This illustrates how the previous research does not explore individuals' subjective, personal experiences of the booty call relationship in which they have engaged.

Therefore, this study will conduct in-depth interviews with young college adults who have previously engaged in a booty call relationship or are currently in a booty call relationship.

The primary objective of this study is to achieve a deeper understanding about the scripts that lead to the development, maintenance, and termination of non-traditional sexual relationships, specifically the booty call relationship. As stated by Littleton and Axsom (2003), individuals tend to rely on sexual scripts especially when they are engaging in sexual activity with a partner with whom they do not have a committed or established relationship because they are not able to draw from previous experience. Thus, the following research questions will be addressed in this thesis: 
RQ1: What behaviors and expectations characterize the script that leads to the development, maintenance, and termination of a booty call relationship?

A secondary objective of this study is to better understand how alcohol and technology influence the development, maintenance and termination of the booty call relationship. As stated previously, research has indicated that the presence of alcohol is strongly associated with the initiation and maintenance of non-traditional sexual relationships. Therefore, the present study will investigate the role that participants perceive alcohol to play in the script for the booty call relationship.

RQ2: How do participants perceive the role of alcohol in the booty call relationship?

Regarding technology, research has shown that telephone calls are the most common way to initiate a booty call "hookup," once the booty call relationship is developed; however, with the prevalent growth of text messages used as a primary channel for communication, the present study will research whether text messages have replaced the telephone calls for the booty call “hookups."

RQ3: What forms of communication are most prevalent in establishing, maintaining, and terminating a booty call relationship?

Research suggests that women tend to view their involvement and perceptions of booty call relationships as more emotionally charged than men (McGinty, Knox, \& Zusman, 2007). Based on the review of the literature, these 
emotions that are elicited could influence the development, maintenance, or termination of the booty call relationship. Therefore, the role of both negative and positive emotions that are elicited in both men and women in all stages of the booty call relationship will be studied.

RQ4: What role do participants feel negative and positive emotions play during the development, maintenance and termination of the booty call relationship?

\section{Conclusion}

This review of literature set a foundation for this present study by focusing on schema theory, script theory, and sexual script theory. A comparison of past and modern dating attitudes demonstrates that nontraditional sexual relationships are prevalent among college campuses. Even though there are multiple types of non-traditional sexual relationships (e.g., one night stands, hookups, and friends with benefits), past research has lacked focus on the booty call relationship. The present study will focus on the booty call relationship, along with the various factors (e.g., alcohol, technology, emotions) that may influence or hinder this specific type of relationship. To better understand the scripts that are associated with the booty call relationship, it is important to focus on the development, the maintenance, and the termination of booty call relationships among heterosexual young adults. The following chapter will present the qualitative methods used to in this study to reach these goals. 


\section{CHAPTER II}

\section{METHODS}

The previous chapter focused on explaining script theory and sexual script theory to set a foundation for this research study. The chapter also focused on explaining past dating attitudes and modern dating attitudes among men and women in the American culture. Then, the different types of nontraditional consensual relationships, specifically booty call relationship and the various factors (e.g., alcohol, computer mediated communication, emotions) that could influence the initiation, relational maintenance, and termination of these relationships were explained. Booty call relationships are underresearched; yet because they are very prevalent on college campuses with $30 \%$ of young adults engaging in such relationships (Jonason et al., 2009), these relationships merit investigation. Since there is a defined script for traditional dating relationships, the primary objective for this study is to identify a potential script for the booty call relationship.

\section{Participants}

The 20 participants I gathered for this research study were primarily from the Midwest; however, four participants were from Texas, New York, Washington, and Wisconsin. For this study, I recruited ten male and ten female 
participants. In terms of age, the participants were between the ages of 19 and 24, since I was looking at young adults who are currently attending college Participants were required to currently be in a booty call relationship or have previously engaged in a booty call relationship.

In order to collect participants for this study, I started out by utilizing a convenience volunteer sample. First, I posted a Facebook status (See APPENDIX A) that explained my research interests and gave my contact information for any volunteers. From this, I utilized a snowball sample, since this Facebook status resulted in 10 of my Facebook friends "sharing" the status to help recruit participants. Second, I sent out an email (See APPENDIX A) to my colleagues and graduate student peers within the School of Communication, explaining my research interests. This email asked them to forward my information to their students or anyone they may know who might wish to volunteer as a participant in my study. I anticipated needing to post multiple Facebook statuses and send out multiple emails to ensure maximum participation; however, I acquired enough participants to complete the study from the first Facebook status and email.

By using snowball sampling to collect data, I asked participants to notify other individuals who might be interested in taking part in my study. This means that those receiving the invitation could give the necessary information to whomever they wanted, provided the participants met the criteria and they chose to contact me. In an effort to address ethicality and avoid any type of coercion, I did not ask friends to take part in the study. 


\section{Data Collection}

The design of this study is qualitative in form, because I wanted to find information about the personal experiences that come from engaging in booty call relationships and how these relationships are developed, maintained, and terminated to help identify the sexual scripts that individuals engaging in booty call relationships employ and/or develop. Qualitative methods allow scholars to explore a topic in an in-depth and unstructured way to aid in generating richer understandings of the full range of opinions and experiences on that topic (Creswell, 2007).

Interviews and solicited stories can help the researcher to learn the personal experiences, to find out the "why" that is behind the "what," and to understand the viewpoint from one individual without that person being affected by the views of other participants (Creswell, 2007). According to Fisher (1987), interviews are the best way to provide understanding because they reveal facts, values, reason, and emotion. Fisher notes that the Greek word logos originally included story, reason, rationale, conception, discourse, and thought, which are all forms of human communication. By using interviews for the study, I was able to gain a better understanding of the reason behind why booty call relationships are developed, how the relationship is maintained, and the rationale for terminating the relationship.

The method I used was in-depth interviews; therefore, I acquired as many participants as necessary to achieve redundancy. In other words, I interviewed participants until the responses presented repeated themes across 
the individuals. (Creswell, 2007; Lindlof \& Taylor, 2011). I estimated about 1015 participants would provide redundancy. I was able to obtain 20 participants, and reached redundancy after interviewing 14 . Even though I reached redundancy after interviewing 14 participants, I analyzed 20 interviews for a richer analysis and more examples.

In this study, I specifically used respondent interviews, as I asked individuals to explain their opinions, determine the reasons behind their opinions, and better understand their attitudes and actions with thematic development across interviews, rather than presenting each participant's perspective uniquely (Lindlof \& Taylor, 2011). Furthermore, I interviewed individuals one-on-one on sensitive and personal topics, and I asked these individuals to "disclose their subjective standpoints" regarding their experiences (Lindlof \& Taylor, p. 179).

To ensure that the participants felt comfortable (Lindlof \& Taylor, 2011), they had the freedom, within reason, to choose when and where the interview was conducted. Out of the twenty interviews, twelve of them were conducted in my personal office in Fell Hall at Illinois State University. The interview was conducted in a protected environment, which helped participant from feeling preoccupied, stressed, energized, or fatigued (Lindlof \& Taylor, 2011).

Each interview lasted from 30 to 60 minutes. Although face-to-face interviews were preferred and I attempted to accommodate as much as possible, eight interviews had to be conducted through the telephone. Many 
scholars argue that telephone or computer-mediated interviews are not the best way to conduct in-depth interviews; however, some scholars argue that these computer-mediated interviews can still provide rich data (Creswell, 2007; Lindlof \& Taylor, 2011). I conducted these interviews within protected environments, both for them and me, as the interviews took place in my office.

Before I asked questions directly related to my research, I read the participant an informed consent statement (See APPENDIX B). The informed consent explained to the participant the general topic being researched, the general preview of the questions to be asked, provide guarantee of confidentiality, and elaborate on any latent risks involved with participating in my study. The consent statement also provided my participants with my contact information, in case they wanted any clarification pertaining to the study.

After receiving oral consent from the participant, I asked questions in a semi-structured interview format. According to Bernard (1988), semi-structured interviews are beneficial when there will not be more than one chance to interview the participant. A major advantage of semi-structured interviews is that the investigator is in control of the process of obtaining the information, but is free to follow new leads as they occur.

Since I interviewed strangers, to begin the interview, I established rapport with each participant (Lindlof \& Taylor, 2011). I established rapport through self-disclosure and explaining why I have chosen this specific area of research. Specifically, I shared with each participant how I became interested 
in the topic of booty call relationships after listening to my friends' experiences and being enrolled in an emotions seminar where we extensively discussed non-traditional sexual relationships. Since the research topic is considered a sensitive area, I began the interview by asking for nonthreatening participant self-disclosure, specifically asking questions about their demographics.

As the interview protocol was semi-structured, I employed an interview guide when asking questions to the participants. The interview guide offered me freedom to ask similar questions to each participant, while still accommodating to each individual (Creswell, 2007). I asked both non-directive and directive questions. Non-directive questions permitted participants the freedom to use their own terminology to explain their experiences about their booty call relationship. Non-directive questions also included "grand-tour questions," which "prompt subjects to tell us how something in their life has transpired" (Lindlof \& Taylor, 2011, p. 202). In other words, these tour questions allowed participants to explain how their booty call relationship were initiated, maintained, and terminated. Directive questions helped the participants "think comparatively or contrastively about a topic" (p. 207), which helped them to elaborate on the questions. To end the interview, I asked "loose-ends questions" to ensure topics that were not covered earlier in the interview are still explored (p. 210).

Specifically, the main line of questions in the interviews was as follows. First, I began by asking my participants how they would define a booty call 
relationship, where they first learned about booty call relationships, and their perceptions of booty call relationships. This allowed me to progressively introduce the participants to the line of sensitive interview questions that was to follow. Also, these questions ensured that the participant did understand that they participated in a booty call relationship rather than a friend with benefits relationship. The next set of questions was more sensitive, as I asked the participants to talk about how their booty call relationship was developed. Specifically, I asked the interviewees to tell me the story of how the relationship was developed, why they chose to enter a booty call relationship, and finally the emotions they were experiencing or had experienced. Then, I transitioned into the maintenance section, where I asked the participants what channel of communication was used most frequently with their partner, how each booty call hook up would be initiated, how they would communicate with their partner about each hookup, the influence of alcohol within the relationship, and again, any emotions they were experiencing from the relationship. Finally, the last set of questions focused on the termination aspect of the relationship. If the relationship had been terminated, I asked the participant to share the story of how it was terminated, why they chose not to enter a serious committed relationship with their partner, and any factors that lead to the termination. On the other hand, if the participant was currently in the booty call relationship, I asked why they were not wanting a committed relationship, how they would feel if the relationship ended that day, and any factors that might potentially lead to the termination. On the rare chance that 
the booty call relationship had lead into a romantic relationship, I asked the participant to tell me the story of how it transitioned into a romantic relationship. To end the interview, I allowed the participants to include any information that I may not have asked (See Interview Protocol, Appendix C).

\section{Data Analysis}

Each respondent interview was digitally audio-recorded, and I kept all audio files on my personal computer in password-locked, encrypted files. When analyzing the data, I began by transcribing each interview. These transcriptions were a verbatim account of the interview and represented the interview in a complete, readable and understandable way. Furthermore, each participant was given a pseudonym to protect his or her privacy. A total of 217 pages constituted the transcribed interviews

I conducted a thematic analysis so I could holistically understand how relationships between the categories reoccur. To do so, Braun and Clarke's (2006) thematic analysis was used. Specifically, their notion of "keyness" was used to highlight specific themes found within the transcriptions. To begin the coding process, every line of the interviews was analyzed to generate themes. While doing a thematic analysis, I considered the tenets of sexual script theory and script theory to arrange the themes that were found. According to Braun and Clarke, thematic analysis is defined as "identifying, analyzing, and reporting patterns (themes) within data. It minimally organizes and describes your data set in (rich) detail. However, frequently it goes further than this, and interprets, various aspects of the research topic" (p. 79). Braun and Clark list 
six ways to conduct a thematic analysis: 1 ) becoming familiar with the data, 2) generating initial codes, 3) searching for themes, 4) reviewing themes, 5) defining and naming themes, and 6) producing the report (p. 82).

From this, I was able to compare experiences across themes (Baxter, 1991). I analyzed the data inductively, without a priori categories (categories created based upon previous research or research; Lindlof \& Taylor, 2011), which led to themes unique to the participants' experiences. Thematic analyses provided insight into the initiation, maintenance, and termination of the booty call relationship.

Specifically, for research question one, I looked for themes that represent the key components of the booty call relationships. Also, I looked for behaviors and expectations within the sexual scene that could lead to the event script of the booty call relationship. For research question two, I looked for how the role, function, and frequency of alcohol were used in the initiation, maintenance, and termination phases of the booty call relationship. For research question three, I coded for themes that illustrated the direct communication between the two individuals through text messages and how it lead to a booty call hook up. In addition, I also coded for the frequency and impact text messages had in each phase of the booty call relationship. Finally, for research question four, I coded for themes of both positive and negative emotions that were elicited in the individuals and either progressed or halted the booty call relationship throughout the initiation, maintenance, and termination phases. 


\section{Conclusion}

In conclusion, collecting data through qualitative means, specifically in-

depth interviews, allowed me to understand and develop the themes for booty call relationships. This method provided me with a holistic understanding of experiences, by allowing my participants to define and explain their unique situations. By doing a thematic analysis, I was able to organize themes that have emerged consistently throughout the interviews, and therefore identify themes that characterize booty call relationships. The following chapter will present the findings that are in accordance with the research questions. 


\section{CHAPTER III}

\section{FINDINGS}

In the previous chapter, I outlined my methodology, which included descriptions of in-depth respondent interviews. In total, I obtained 20 interviews, each lasting approximately 30-60 minutes in length. After transcribing and analyzing the interviews, I was able to identify the salient themes. In this chapter, I will review the themes that emerged. First, I will present how participants defined a booty call relationship. Then, I will present the results in the order of my research questions.

\section{The Booty Call Relationship}

The first research question sought to identify the behaviors and expectations that characterize a potential sexual script for the booty call relationship. However, before the script of the booty call is discussed, the prototypical schema must first be considered.

To begin, schemas and scripts can often be confused with one another. In short, the core idea of schemas is that they are like a mental template that describes the key features of representations of objects, settings, or situations (Stockwell, 2006). Scripts are a temporally ordered schema, or rather, a subtype of schemas that describe the key features of an activity. In addition to scripts, most scripts describe the role, props, lines, and results within the 
event (Emmott \& Alexander, 2011). The next section will discuss the prototypical relational schema that is found within booty call relationships.

\section{What is a Booty Call?}

As stated in the aforementioned literature, a booty call relationship is defined as "the solicitation of a non-long term partner for explicit or implicit intent of engaging in sexual activity" (Jonason et al., 2009, p. 460). Learning through friends, magazines, music, movies, and reality television shows, participants were able to explain what makes up a booty call relationship. I asked the participants to define a booty call relationship to ensure that they knew what a booty call relationship was and that they were, or had been, in a booty call relationship rather than one-night stand or a friend with benefits relationship. The participants had very similar definitions and were able to describe the main elements of a booty call relationship. For example,

"I would define it as regularly having sex with someone, but there is no emotional attachment and you just let the person you know you are in it for sex." (Ryder)

“I would define a booty call relationship as something where you're just having sex with another person, there is no relationship, like its just sex--there is no conversation or emotional attachment" (Jackie)

"I would define a booty call relationship as when you have sex with someone, like you are repeatedly hooking up with them, but there is nothing else to the relationship" (Katie) 
"A booty call relationship is a relationship where two consenting partners are using each other for sexual intercourse, whether it is oral or vaginal or anal and there is a mutual understanding about the relationship, and how it will not turn romantic" (Seth)

"I think a booty call relationship is basically when you text someone because you want to hook up and there is no substance to the relationship" (Tracy)

The participants explained that they first learned about booty call relationships through a variety of sources such as friends, siblings, reality television shows, magazines, music and movies. Even though they were all learning about booty call relationships from different sources, they are still able to consistently define a booty call relationship that similar to Jonason et al.'s (2009) definition.

Since participants are able to agree on what constitutes a booty call relationship, it shows that there is a prototypical relational schema about booty call relationships. The elements that are included in this relational schema include: two consenting individuals, sexual intercourse, and no expectation of a romantic relationship to be developed. Even though these elements are consistent in each booty call relationship, there are still variations among each type of booty call relationship.

The transcription and analysis of all 20 interviews yielded a consistent event script for booty call relationships. There are commonalities among participants' experiences with their booty call relationship that hold this script 
together, despite nuances of difference among the experiences. First, to illustrate the variations among the relational schema in booty call relationships, I will share four booty call stories.

\section{The Booty Call Experience}

Elizabeth's story. Elizabeth is a 22-year-old Washington state native. Elizabeth had just gotten out of a three-year committed relationship, but realized

I have needs, but I don't want a relationship so I just need to find someone who is okay with just hooking up and being my booty call. Also to have them be okay with just having sex, like no hanging out or no talking or anything like that.

Her roommate introduced her to Cody, who was also looking for a similar relationship. After a night out drinking, Elizabeth and Cody exchanged numbers. The next day, Elizabeth texted Cody and they made plans to meet up. After their initial hookup, whenever one person would text the other, they knew it meant, "Do you want to hookup?" Even though they would engage in small talk before asking to hookup, they would never communicate outside of the intention of hooking up. Once they would agree to meet up, he would come over to her residence. The moment he got to her apartment, they would hook up and he would leave immediately after they were finished. Alcohol played a major role in the reason they would decide to hookup; furthermore, Elizabeth's friends encouraged her to stay in this relationship. Elizabeth stated, "My 
friends were always encouraging me to stay in this relationship because they liked that I was getting over my ex."

Three months into the relationship, they started to hook up less often. Elizabeth shared "He texted me a couple times asking me to hook up and I never answered him, because I was not in the mood and so it kind of just fizzled out because of that." When the relationship ended, Elizabeth did not feel any emotions but she did state "I think by being in this booty call it helped me get ready to be in a romantic relationship with another person...so I guess in the end, you could say I was grateful for this booty call relationship."

In sum, Elizabeth had the type of booty call relationship that is often portrayed in the media and in literature, such as she and her partner hooked up, never talked about the relationship, and then it ended without any confrontation.

Based on the definition of the booty call relationship, we might assume that it is possible to set a universal sexual script; however, this is not the case. As it can be seen in Elizabeth's story, she experienced a very stereotypical booty call relationship. When starting this research project, I assumed that every booty call relationship would be like Elizabeth's and that they would lead to a discovery of a sexual script. The next three stories illustrate the uniqueness of each booty call relationship.

Thomas's story. Thomas is a 23-year-old Illinois native, who has been in two booty call relationships. Thomas entered a booty call relationship with his roommate's ex-significant other, Taylor. Thomas stated, “Taylor and I were 
hanging by ourselves, which was odd because it never happened before because we weren't like friends and we were drinking, and yeah, we hooked up." When asked why he entered the relationship, he said, "I think the opportunity presented itself and I took it. That was like the only reason I entered the relationship." Thomas and Taylor also spent a lot of time together, since they were both active in the same organization; thus, they decided to keep the relationship a secret. To communicate with each other, Thomas and Taylor would text each other. However, they would engage in more dialogue than in Elizabeth's story. As Thomas explained,

It would start off with an anecdote about something that happened in our organization over the weekend, like a joke about something or saying something irrelevant to our sexual relationship, it was just kind of friendly...then about fifteen minutes into the conversation we would kind of maybe flirt a little heavier and then one of us would be like "What are you doing right now?" or "Do you wanna hang out?, which meant “Let's hookup."

They would always meet up at Thomas's house and " $90 \%$ of the time we were drinking" before the hook up occurred. Furthermore, there would be other people over at Thomas's residence; therefore, Thomas and Taylor would have to wait until they were alone to hookup. Due to the fact that the relationship was secretive, Taylor would have to pretend to leave and then come back once everyone else dispersed. Usually, Taylor would leave when the other guests left, only to come back to Thomas's apartment "five minutes or so 
later." After the hookup, Thomas and Taylor would still hang out and even spend the night with each other.

This relationship had a brief period for one month where they stopped hooking up. Over Christmas break, Taylor started dating another man and kept it a secret from Thomas. As Thomas stated, "I found out that Taylor was in a relationship with this guy, and I felt jealous. I was also upset because I didn't even know Taylor was even talking to other people." When asked about how they started hooking up again, Thomas shared,

We were hanging out with a bunch of people and it was at my house, and we all got really drunk and for some reason, Taylor and I were the last ones up. It's interesting because we did not have any sexual encounters that evening but we did talk about our relationship. We told each other our sides of the story, and we decided we were not going to have sex. We went to sleep, but the next day we got dinner and talked about getting past what happened because we weren't speaking like friends anymore, which was sad, like we were acting like we didn't know each other...and once we started talking like friends again, the booty call relationship started all over.

Over the summer, Thomas and Taylor were not in a close proximity to engage in repeated sexual encounters; however, that did not stop Thomas from always thinking about Taylor.

I constantly had my mind on her. There were times where we would speak about anything I could find to talk about, which still wasn't very 
often because I didn't want to come off as clingy or anything. I was trying to be good, but I just could not get my mind off of Taylor. I was actually with another person for like a good two and a half months, but I wasn't interested in the relationship. It was undeniable that I wanted to be with Taylor so I just had to accept that. Later on, Taylor told me that she couldn't stop thinking about me either. In August, we talked and we decided to start an actual relationship.

This booty call relationship was developed between two acquaintances and by spending so much time together, eventually a friendship formed, which in turn lead to wanting more than a booty call relationship. While most booty call relationships have the intention of not turning into a romantic relationship, this particular booty call relationship did progress into a traditional committed relationship. Less than $12 \%$ of booty call relationships will progress into a committed romantic relationship (Eisenberg, Ackard, Resnick, \& NeumarkSztainer, 2009; Jonason, Li, \& Richardson, 2010).

Kathy's story. Kathy is a 22-year-old Nebraska native who has been in three booty call relationships. In this example, Kathy entered a booty call relationship with a college acquaintance, Alan. She explains, It's hard to explain our preexisting relationship, I mean, we went to college together, and we had mutual friends and we were Facebook friends and followed each other on Twitter and we would go to the same parties but not really talk or interact. So I don't know, we weren't 
friends...and I'm not sure if you could even say acquaintances...like we knew who each other was but that's about it.

The relationship between Kathy and Alan did not start out as a booty call relationship but rather, a relationship with dating intentions. One summer night, Alan gave Kathy his cell phone number and from that, they started talking, via text messages, daily. Three weeks of texting back and forth, Alan made a trip to visit Kathy. As Kathy explained,

We went out to the bars and I was fine because I told myself I was not going to get drunk. Well after the bars closed, we went back to our mutual friend's house and proceeded to drink a lot. Around $3 \mathrm{am}, \mathrm{I}$ realized the time and decided I needed to go home, so he followed me outside, and one thing lead to another and we hooked up. But the hook up was really bad, like horrible, and I don't quite remember but I'm guessing I must have joked about it, because over the next few days he didn't answer any of my text messages.

After the hookup, Alan did not talk to Kathy at all, which made Kathy "feel used because I thought he liked me and wasn't going to use me just for sex." A month after the horrible hookup, Alan was back in town for a summer festival and they ran into each other at a bar. Kathy explains,

I was drunk and I was feeling ballsy so I texted him saying I wanted a redo. I watched him look at his phone, read the text and ignore it! I was pretty pissed. So I started drinking more and around 2 a.m. when I got 
home he texted me back, asking where I was. I told him my address, he came over, and we hooked up again.

In August, Kathy, a recent college graduate, moved to another state for her career. However, anytime she planned to travel back to Nebraska, she would tweet or post on Facebook about her return. From these social media posts, Alan would text Kathy to see if she wanted to hang out while she was back. As Kathy shared,

It's like he has some sixth sense of when I am coming back, even if I wouldn't post on Twitter or Facebook that I was coming back, he would always start texting me to see when I was coming back and I would always agree to meet up.

This lead to a long-distance booty call relationship, since they would always plan to hook up whenever Kathy was back in Nebraska. If Eric would ever text Kathy, knowing she was not in Nebraska, the conversation would quickly lead to sexting and him sending explicit pictures. Kathy rationalized, "It would turn to sexting pretty quickly and he would send me dirty Snapchats, and I think this was just our way of keeping each other interested until the next time I was back in Nebraska and we could hookup.

Currently, Kathy and Alan are still in the long-distance booty call relationship, which has been going on since May of 2012. When asked about the emotions she was experiencing due to this relationship, Kathy shared, “I don't really feel any emotions for him. It's fun to hook up with him, but I'm not really expecting any thing more. I mean like, when he texts me I feel happy, 
but otherwise I don't feel anything else for him." From this response, I was prompted to ask why they have chosen not to enter a romantic committed relationship, and Kathy explained,

I just don't think he is a good person. I mean he isn't someone I could have a serious conversation with and I think I would worry about him cheating on me all the time, because he hooks up with me and I know he is talking to other girls at the same time. I just don't think I could trust him.

The new phenomenon of long-distance booty call relationships is an interesting concept. Most individuals who are engaged in a booty call relationship are close enough in proximity that it would not require traveling a long distance. Long-distance booty call relationships will be elaborated later in the discussion chapter. Not only was this specific story a long distance booty relationship, but it has also lasted for over 18 months and in that time frame, has not turned into a romantic committed relationship.

Seth's story. Seth is a 24 year-old Wisconsin native who has only been in one booty call relationship. He entered a booty call relationship with Ava, who was a work colleague. They had worked together for about a year, and as to why Seth entered this booty call relationship, he explained,

We were work colleagues but once in a while we would hang outside of the work office with a group of people and so there was this comfort. I felt as if this person was nice and a genuinely smart person and I figured we would work well physically together. Also from what I knew about 
her, I knew she would be down with a booty call relationship and it was something I always wanted to try.

Seth explained that it took lot of hinting to Ava that he was sexually attracted to her and wanted to engage in sexual relations with her. Seth would talk to Ava at work and started texting her more frequently. As Seth shared, "I was using this ambiguous language to kind of test the waters and see how she felt about me and if she was interested." Finally, when Ava caught on to the advances, she showed interest in entering a booty call relationship with Seth by making, "explicit comments and being direct about what she wanted." For this relationship, Seth explained that Ava established a lot of ground rules about the relationship before hooking up. These ground rules included: only meeting at his place, since he lived alone, not developing any emotions or wanting a romantic relationship, and keeping their relationship an absolute secret. Seth explained how keeping it a secret was the biggest rule of all, "I think one of the main reasons why we kept it a secret is because we were work associates and we didn't want people to look at us weird or talk behind our back about us." Research shows that although young adults typically rely on friends as their main source of sexual information and story sharing, they will not fully disclose personal stories that could be seen as promiscuous (Holman \& Sillars, 2012). In addition, women who express their casual sex experiences tend to be viewed unfavorably by society, thus they tend either to not engage in causal sexual relationships or to keep them secret (Crawford \& Popp, 2003; Milhausen \& Herold, 1999). 
While in this booty call relationship, Seth and Ava would both initiate the hook up by texting each other a specific emoji (a stylized emoticon available on many text phones), which was code for "Let's hookup." Furthermore, they would engage in dialogue without the goal of hooking up. Seth and Ava would talk about anything from their jobs to their future plans. In addition, even though Ava would never stay the night, they would hang out after the hook up and self-disclose more information. From all of this selfdisclosure, Seth started to develop feelings for Ava. Seth shared, I felt a strong connection with Ava when we started the booty call relationship and deep down I had some emotional connection. I was gravitating towards her because I did like her as a person. And as the relationship progressed, I found myself growing attached to this person, and I was feeling more comfortable around her. I started to think that maybe we could turn this booty call relationship into something more, because we are sexually compatible, and she is funny, and she is smart, and she is nice and I thought "and you know, the sex is good, what am I doing? Am I an idiot? Am I starting to fall for a person who we set strict guidelines that we were only going to have sex? Am I going crazy right now or is it just the hormones taking advantage of my brain?" I had a lot of weird moments like that and had a lot of self-reflective thinking about the relationship.

It was clear to Seth that he wanted something more than a booty call relationship. Townsend (1995) found that $12 \%$ of men agreed that they wanted 
to be emotionally involved with a person before having sex with a person. Furthermore, $25 \%$ of men agreed that, even if they had no emotional commitment at the beginning, after several instances of sex they do experience emotional vulnerability and wish for a romantic connection.

Even though Seth was becoming more emotionally attached to Ava, he kept his feelings a secret. He shared,

I definitely kept my feelings for her a secret, because of the ground rules. I felt like she was way more intellectually and emotionally competent to engage in this kind of relationship, and I was just thinking "Why would I ruin this relationship by telling her that I like her more than just a booty call when she explicitly stated in the ground rules that there would be no emotional connection?"

The emotional connection that Seth was wanting with Ava was the reason for the termination of their booty call relationship after only two months of being a booty call relationship. Seth eventually started to decline Ava's sexual advances, by stating that he was not feeling well or was not available. Seth never explicitly stated that the he wanted to end the relationship, but assumed that Ava got the hint after a while because she stopped texting him to see if he wanted to hookup. Once the relationship was over, Seth was experiencing a lot of negative emotions, as he shared, I felt like shit. I felt so much remorse and sorrow, and I felt as though I had let this really awesome person slip away because I had some level of uncertainty within myself or that I gave her the wrong impression and I 
just had a lot of guilt that I wasn't able to express. I also don't think she felt much emotion, because whenever I saw her in the office she acted like everything was normal.

Grello et al. (2006) found that men in casual sexual relationship had few depressive symptoms than compared to women. However, with Seth's booty call relationship experience, it shows that this is not always the case. Owen and Fincham (2011) found that $25 \%$ of men had hoped that their casual sexual relationship would progress into a committed relationship.

In conclusion, within any schema prototype, there could be miscommunication because of uncertainty, blurring between the boundaries, or lack of communication, which might explain some of the divergences in the variations of the booty call relationship. Furthermore, these four different stories demonstrate how individuals in the booty call relationship get "on" and "off" stage, which leads to the sexual event script.

\section{The Sexual Encounter}

While there are variations among the relational schema in the booty call relationships, there is a consistent sexual event script. This sexual event is a scene within the larger play of the booty call relationship. As stated earlier, scripts describe the role, props, lines, and results with a specific event (Emmots \& Alexander, 2011). Throughout this section, the key scene of booty call relationships will be discussed.

Role. It is evident that the role of the booty call relationship is to achieve sexual satisfaction without being in a traditional romantic relationship. 
As Ryder states, “I wanted sex but I didn't want to develop feelings for this person." Jackie also shared similar expectations about the role of the booty call relationship, “I felt like hooking up with someone but I didn't want anything serious."

Props. The props in the sexual scene include the influence of alcohol and the utilization of text messages. Both of these props were major factors in leading up to the sexual event. Specifically, alcohol was used to gain courage to initiate the sexual event and to lower inhibition while engaging in the sexual act. As for text messages, participants used these as the primary way to get into contact with their partner to see if they were interested in hooking up. The roles of alcohol and text messages were so prominent within the research that they both merit their own discussion, which will be discussed later.

Lines. In the key sexual scene of the booty call relationship, there were common lines used to initiate the sexual encounter. First, the lines "Wanna hang out?" or "You busy?" were most frequently used to show interest in wanting to hook up. As Eric shared, "One of us would text the other, 'Do you wanna hang out?' and it was understood between both of us that it meant we wanted to hook up." Kylie also shared, "When either one of us wanted to hook up, we would just usually text "You busy?" because it was straight to the point." These lines that were used to initiate the booty call relationship imply that there is no relational attachment, self-disclosure, or affection within the relationship. If either partner would use lines that suggest any sort of emotional attachment developing, it would violate the script. 
Results. The use of props and lines lead to a result of engaging in sexual activity with their booty call partner. Once the prop of text messages with the broad lines were sent and positively received, the individuals would meet up at a one of their residences. Once they were in a face-to-face context, the main goal was to engage in sexual intercourse rather than to hang out in a platonic sense; therefore individuals almost immediately engaged in the sexual behavior. After the role of sexual satisfaction was achieved, the individual who came over would leave without engaging in post intercourse cuddling or staying to hang out.

As Cindy shared, "After we would hook up, we would be like 'okay, see ya, bye.', so neither one of us would hang around after we hooked up for longer than 15 minutes." Eric also had similar experiences: "Before we would hook up, we would talk for maybe like ten minutes. Then after we were done hooking up, she would lay in bed next to me for maybe like five minutes and then she would find an excuse to leave."

Overall, the use of roles, props, lines and results were used to set the sexual event script for the booty call relationship. In most cases, the sexual event script of the booty call relationship went as follows:

1) Consume alcohol

2) Send a text message to the partner to gauge partner's interest in hooking up, usually through a broad message such as "Wanna hang out?" or "You busy?"

3) Meet in a face-to-face context 
4) Engage in the sexual acts

5) Leave immediately after receiving sexual satisfaction In conclusion, through the in-depth interviews I was able to identify a sexual event script about the booty call relationships. While there is variation in the relational schema of each booty call relationship, there is a consistent sexual event script. As stated earlier, the reoccurring props of alcohol and text messages used in the booty call relationship were so prominent that they require their own discussion, which will now be discussed.

\section{More Alcohol, Please}

In assessing the second research question, I continued with the process of generating themes to determine the ways participants perceived the role of alcohol in the booty call relationship. Two themes were identified that contributed to the influence of alcohol used in booty call relationships: liquid courage and alcohol as an excuse.

\section{Liquid Courage}

Research with college students shows a relationship between heavy alcohol use and risky sexual behaviors (Cooper, 2002). Meilman (1993) found that $35 \%$ of college students, since coming to college, have engaged in sexual behavior that was influenced by alcohol. In more recent studies, Paul and Hayes (2002) found that $94 \%$ of college students believed that alcohol or drugs were frequently used to facilitate hookups.

It is apparent that sexual encounters and consuming alcohol are intertwined, but the nature of this relationship is complicated. One popular 
belief is that alcohol causes "disinhibition, or a release of natural impulses, by eliminating learned inhibitions" (Grant \& MacDonald, 2005, p. 375). As Katie shared, "When we first started hooking up, we would drink because I think he knew I was nervous and it would like help relax me plus, like, drinking is fun." Research among college samples has indicated that both male and female students expect the presence of alcohol during interaction to increase the chance of a sexual encounter between the two parties (Vander Ven \& Beck, 2009). As Maureen stated, "I was tipsy, so like I knew what I was doing and I didn't care because I felt brave thanks to liquid courage."

In this research study, it is evident that alcohol is a large factor in the development and maintenance of the booty call relationship. To begin with the development phase of the booty call relationship, 15 of the 20 participants stated that they met their booty call partner while under the influence of alcohol, thus leading to the first hookup. Maureen shared, It actually started at a party where we both had been drinking...what happened is that this guy was older than I was...by maybe two years...and he was well known and popular at our school and it was because it was small school, everyone knew him as a...slut (laughs). So yeah, I saw him at a party and approached him...and we started talking with the intentions that we were going to hookup.

Kylie had a similar experience, as she told me,

We were at a party and I knew of him, and when we first met and there was alcohol involved... and we started talking...then it just kind of took 
off in a very flirty direction and it was more like, whatever we said to each other, it was hinting that we wanted to hookup, which we did by the end of the night.

Furthermore, almost all of the participants said that as the relationship was progressing alcohol was still an influence in most booty call hookups. Thomas shared, "I would say probably like, $90 \%$ of the times we were drinking before each time we hooked up." While Ryder stated, "We hooked up a lot, like five times a week and so maybe once there would be a hook up where alcohol wasn't involved, otherwise we always drank together before we hooked up."

As this research study shows, alcohol played a large role in the development and maintenance stages of the booty call relationship, as participants would use it as liquid encouragement to start the relationship and to continue the relationship.

\section{Alcohol as an Excuse}

Garcia and Reiber (2008) found that 33\% of undergraduate students reported their casual sexual behavior as unintentional due to the influence of alcohol and other drugs. Alcohol may also be used as a familiar "safety net" for college students, where alcohol is consumed in excess before a potential questionable sexual encounter this way if anything positive or negative happens, it can be justified by being under the influence of alcohol (Vander Ven \& Beck, 2009). Usually, alcohol is used as an after-the-fact justification for unwanted or promiscuous behavior (Vander Ven \& Beck, 2009). In addition, 
alcohol may also serve as an excuse, purposely consumed as a strategy for protection from having to justify hook up behavior (Paul, 2006).

Throughout the development and maintenance stage of the booty call relationship, all participants had at least once used alcohol as an excuse or justification for their behavior. In the development stage, Eric justified his actions by giving his booty call partner his number by saying,

We were friends on Facebook and Twitter, because when you are in college, it's like the cool thing to do to add everyone. Anyways, I was drunk one night, and she commented on a link I posted on Facebook, and for some reason, like I have no idea why, probably because I was drunk but I gave her my number through a Twitter message and told her to text me.

Kathy justified her drunken booty call hook up by saying "About a month later, he was back in town for a festival and we ran into each other at the bar. I was under the influence of alcohol and I was feeling ballsy so I texted him saying I wanted to hookup. If I was sober, there is no way in hell I would have ever texted him saying I wanted to hookup-that would have been embarrassing, but because I was drunk, like, I really didn't care."

For the maintenance part of the relationship, participants were still using alcohol as an excuse for their hook up behavior. Justin said, "We would only hook up if we were both out on the town and drunk. I don't even know if we ever even talked to each other sober. I don't know why, but I would never 
even think about her unless I was drinking, I guess it was like alcohol was the reason I would think of her and want to hook up with her."

Females related similar experiences; Tracy stated, I would say a good percentage of the hookups would have alcohol involved, like we used to drink and then we would go over to his place and hookup. So yeah, alcohol was a big influence in our relationship, but I don't think it changed our relationship, like I never regretted hooking up with him because I was drunk, but it was usually a reason why we kept hooking up.

When it came to the termination stage, alcohol did not play a factor as to why the relationship ended. Fifteen of the 20 stated that the relationship just fizzled out and ended without any dramatic confrontation or any explicit conversation stating that the relationship is over.

\section{“Wanna Hang Out?"}

Research question three addressed the most prevalent form of communication in establishing, maintaining, and terminating a booty call relationship. Research has suggested that telephone calls are the most common way to initiate a booty call "hookup," once the booty call relationship is developed (Jonason et al., 2009); however, in the past few years, texting has become the most popular form of communicating (Piotrowski \& Kass, 2013). Cell phone use is unique compared to other media since the cell phone is transportable and is not limited to a specific area (Garcia-Montes, CaballeroMunoz, \& Perez-Alvarez, 2006). The thematic responses indicated one 
overarching theme in the maintenance and termination stage of the booty call relationship: text messages.

\section{Text Message}

Many adolescents and young adults consider cell phone texting as their primary source of communication (Tulane \& Beckert, 2013). According to Ostrager (2010), nationally there are more than 75 billion text messages sent a month. These young adults perceive texting to be a private and a direct way to communicate with other individuals (Pettigrew, 2009). Furthermore, these adolescents and young adults choose to text for a variety of reasons which include flirting, starting and ending relationships, and facilitating social events (Lenhart, 2010; Srivastava, 2005).

Texting throughout the different stages. The patterns of initiation and maintenance facilitated by mediated communication evident in the interviews align with and support the previous research. While many of the booty call relationships were developed in a face-to-face situation (e.g., party, social gathering), each booty call hook up was initiated through a text message. Eric stated, "It was always through text messages. Sometimes we would Snapchat, but I mean, like it was always texting." This was seen in almost all of the interviews, that both parties would get into contact with each other through texting.

Even though these individuals who were in booty call relationships were texting each other, the conversations held no substance. As explained by Cindy 
when her booty call partner was texting her, a normal conversation would go as follows:

It would be like "Heyyy, what are you doing?" and then "What are you doing tonight?" or “What did you do today?"...and then, I don't know it was basically four or five texts, and then one of us would be like "Come over"...and that was it.

The male participants agreed that their conversations with their booty call partners did not hold any value, but rather they were just trying to be polite until they asked if they wanted to hook up. As stated by Justin,

There were times when she would straight up text me "Come over," but like if I was initiating the hook up, I would try to initiate the hook up by texting her "Hi" or something like that, because I wanted to try and be friendly...but otherwise we would never talk outside of wanting to hook up.

When it came to the termination phase of the relationship, texting was still the preferred method among the participants. Tulane and Beckert (2013) found that $61 \%$ of individuals would break up with someone they are casually dating via text message. Throughout the research in this study, if the relationship was explicitly terminated, it was done through text messaging rather than face-to-face. For example, Justin shared,

I could kind of just tell towards the end of the relationship that something was going on. I found myself texting her more than she was texting me, and her responses were really short, like as if she didn't 
want to talk to me...finally she told me that she was seeing another guy and didn't want to hook up anymore.

\section{Sexting}

It was not always words that were used to initiate a hook up. Individuals would receive sexts as a way to initiate a booty call hookup. "Sexting" is defined as the act of sending and receiving nude or seminude pictures of another via text" (Ostranger, 2010, p. 712). These sexts are meant to be physically or romantically attractive to another person. In fact, sexting has become so popular that this word was competing to be "The Word of the Year" in the New Oxford Dictionary's contest (Stanglin, 2009). For example, Victor described his experience receiving sexts as,

She would text me and let me know she is thinking about me by sending me picture messages, like it will be random, there will be days where I wake up to an explicit picture message from her and I have no idea what triggered this for her, but I know it means she wants to hookup.

In the past making a phone call to initiate a booty call hook up was the norm, but as text messaging becomes more popular among young adults, it is evident that it is the most common way to initiate a booty call hook up between partners. Besides text message being a more convenient and quick way to get into contact with someone, it also removes confrontation. If one person in the booty call relationship initiates a hook up and the other partner

declines the sexual advance, there is not as big of need for face saving strategies, as there might be if it was in a face-to-face situation. 


\section{Emotions}

Research question four addressed how participants perceived the role that positive and negative emotions played during the development, maintenance, and termination of the booty call relationship. Two themes emerged after asking the participants to describe the emotions they experienced throughout each stage of the relationship: excitement and happiness with guilt.

Emotions play a crucial role in human sexual strategies (Buss, 1989; Symonds, 1979). The way that men and women develop emotional feelings towards their casual sex partners are very different. Although it is normal for young adults to explore and experiment with sexual intimacy (Manning, Longmore, \& Giordano, 2005) it is unclear whether their positive and negative emotional reactions after hooking up are related to how they feel about their casual sexual encounters.

\section{Excitement}

Research indicates that females' reactions in casual sexual encounters tend to be negative (Townsend \& Wasserman, 2011). Furthermore, research suggests that for women, "not knowing their partner and the lack of further contact with the partner seemed to compound their regret and anger at themselves" (Paul \& Hayes, 2002, p. 655). However, this was not the case in this study. In the beginning of the relationship, female participants viewed their booty call relationship positively and as exciting. As Cindy stated, "I was just excited because well I don't know, because I did always have a crush on 
him, but once I realized that I didn't want anything else from him, it was exciting...and it was new."

Another participant, Gina, stated it quite directly: “I was happy for sure because it was exciting and new. I also felt really confident in myself because I was hooking up with this attractive guy, and like, it just made me feel good about myself." Maureen shared how she felt empowered in her booty call relationship by stating "I did have a crush on him and I was still really excited about what was going on, and I felt empowered because I was calling the shots.

These results are consistent with Glenn and Marquardt (2001), who found that $62 \%$ of college women felt "desirable" after hooking up. Along with these findings, Owen, Fincham, and Moore (2011) found that not all women experience negative emotions after engaging in casual sex; rather some women found them enjoyable. Along with these findings, Townsend (1998) found that women felt positively about casual sexual relationships when the man appeared to be invested at the level the women felt appropriate, the woman felt in control, and the woman did not need to feel worried or exploited.

Research shows that men tend to feel more positive emotions than negative emotions toward their casual sexual encounters (Townsend \& Wasserman, 2011). Participant comments in this study support the previous research. Men also felt excited at the beginning of the booty call relationship. Ryder stated, "It was exciting and fun to be hooking up without any strings attached." Another male participant, Victor, felt similar excitement when he stated, “There was a thrill going in and messing around with someone I didn't 
even feel bad for hooking up with someone who wasn't my girlfriend because it was so exciting and fun."

\section{Happiness with Guilt}

While most participants described being excited about the booty call relationship developing, many reported a mixture of feeling "happy and guilty" as the relationship began to progress. The mixture of emotions that were elicited from the booty call relationship could be remnants of the latent traditional dating script. In other words, individuals may feel the need to adhere to the traditional dating script by finding a stable relationship with the hopes of getting married rather than engaging in a booty call relationship where there is no desire for a committed romantic relationship.

In the aforementioned literature, happiness is defined as a strong positive emotion that is experienced in the context of obtaining progress toward a goal (Knobloch \& Metts, 2008). Furthermore, happiness has a long duration and makes the individual have a high level of positive energy.

Guilt, however, is defined as when individuals focus on negative aspects of their behaviors, such as "the thing done or undone" (Tracy \& Robins, 2004, p. 106). Guilt is elicited by internal attributions and results when unstable aspects of the self are blamed (Gilbert, 2003).

Thomas shared his mixture of feeling happy and guilty by stating, I was happy because I was also, like, liberated, and I had sexual freedom and sexual satisfaction, so yeah, I was happy. But also, I felt guilty because my partner had previously been in a relationship with one of my 
good friends and I felt guilty because I knew I was probably hurting my friend in some way. I don't know though, I think the happiness outweighed the guilt most of the time.

Feelings of guilt often create a desire to reevaluate one's moral compass and make the guilt-induced behavior disappear (Hartz, De Rivera, and Mascolo, 1995). Therefore, individuals will engage in reparative action such as apologizing to undo any harm that was done. In this example, guilt was induced by the fact that Thomas was breaking a trust with his good friend. Guilt evolves from a system of caring and avoiding doing harm to others (Tracy \& Robins, 2004). Eventually, Thomas came clean about the relationship and the friendship was stable once again.

Ryan felt guilt but not for the same reason as in the previous example, As it was sexually satisfying, it wasn't satisfying in any other ways. I felt really guilty because like I never thought I would be the type of person who would enter this type of relationship. But you know I also was happy because it was sex and it was good.

General sexual satisfaction refers to an overall, inclusive appraisal of the quality of one's sex life (Holmberg \& Blair, 2009). It has also been found that men report a higher level of sexual satisfaction compared to women (Laumann et al., 2006). Guilt is a powerful motivational and regulatory force in an individual's daily life (Goa et al., 2010). In order to feel this guilt, Ryan engaged in metacognition, the ability to reflect and judge one's own thinking and feelings in one's mind (Gilbert, 2003), and thus, made him feel guilty for 
engaging in a booty call relationship.

There was still a third type of guilt being felt by the male participants; Seth explained this,

I think I was all over the place with my emotions. I mean like, I was excited, and happy that I was in the relationship with her...but also, I was sad when she left right away, and every time I would see her in the work environment I would feel a little bit of guilt because in the sense that I was using her as a sexual outlet, even though she was doing the same thing with me.

Past research indicated that males would feel guilt or shame when they felt that their partner was not attractive enough and/or their partner was too promiscuous (Townsend \& Wasserman, 2011). However, this study shows that men have a variety of reasons as to why they feel guilty while being in a relationship.

The mixture of happiness and guilt was not exclusive to men; women also felt the same combination of feelings when in a booty call relationship. Kylie stated,

I sometimes felt guilty, because I had just gotten out of a serious relationship, and I felt like I was cheating on my ex-boyfriend even though, like, he was my ex-boyfriend. I don't know though, I mean, I also felt happy because my booty call partner was fun to be with. 
Furthermore, other female participants were also feeling guilty, as Tracy stated,

I was happy because I was having sex, but like I was also feeling guilty because I felt like he was starting to develop feelings for me and so I felt guilty because I didn't have those same feelings for him.

\section{Conclusion}

In sum, from the transcribed data, there were not enough commonalities to set a universal sexual script for the booty call relationship. It was very clear in the data that alcohol played a key role in the development and maintenance stages of the booty call relationship. Furthermore, due to the rise in text messages as a primary form of communication, individuals would initiate each booty call hook up through a text message. Not only would individuals text each other to initiate a hookup, but they would also engage in sexting to keep each other interested in the relationship. In addition, if the termination was explicitly talked about, it was done through text messages. Finally, participants described how they felt both happiness and guilt while in the booty call relationship. In the following discussion, I will elaborate upon themes that emerged outside of the research questions, as well as provide practical applications to the data. 


\section{CHAPTER IV}

\section{DISCUSSION}

The goal of this study was to address the lack of research on the sexual script of non-traditional consensual relationships. In doing so, I focused specifically on one type of relationship: the booty call relationship. While the booty call relationship as been studied, little research has been done on identifying the sexual script of the booty call relationship. This study partially fills that gap by exploring the initiation, maintenance, and termination of the booty call relationship to try and set the script.

To that end, I conducted in-depth respondent interviews with 20 college-aged individuals who was currently in or has engaged in a booty call relationship. Through qualitative research, I was able to better understand their booty call experience, their perception of alcohol and text messages within the relationships, and how both positive and negative emotions impacted the relationship.

I will begin the discussion by explaining themes that emerged outside of the research questions. Thereafter, I will distinguish strengths and limitations to the study, and avenues for future research. 


\section{Additional Themes}

The primary objective of this research study was to try and identify the sexual script of the booty call relationship. Furthermore, a secondary objective was to also achieve a better understanding of how participants perceived alcohol, text messages, and emotions as a factor of their booty call relationship experience. While all the research questions were thoroughly explained, the data revealed additional themes that did not align with answering the research questions.

\section{Long-Distance Relationships}

What constitutes a long-distance relationship can be based on a number of factors, such as physical geography, miles traveled, or time spent traveling (Pistole \& Roberts, 2011). Stafford (2004) found that $25 \%$ to $50 \%$ of college students are in a long-distance relationship. The research conducted on longdistance relationships is almost exclusively focused on romantic committed relationships; however, this research study suggests that individuals are engaging in long-distance booty call relationships. As it was explained in chapter three, Kathy is currently engaged in a long-distance booty call relationship, yet she was not the only participant who had been in longdistance booty call relationship. As Victor shared,

It was kind of a long-distance relationship, like we didn't go to the same college, but we would hook up whenever I was back home. Even while I was away at college, I would get explicit pictures and she would always text me if she knew I was going to be back home. 
Furthermore, Eric shared his long-distance booty call relationship by stating, "We lived in the same town when we started hooking up, but she eventually transferred schools, but we would still hook up whenever she was back in town. It was like we didn't want to stop hooking up just because we weren't in the same town anymore."

A fourth participant, Katie, also indicated that her and her booty call partner did not live in the same town. In fact, they lived 40 minutes apart. Even though they lived in separate towns, they would frequently drive to each other's residence just to hook up.

While only one fifth of the participants implied that they were in a long distance booty call relationship, it was substantial enough to recognize that long-distance booty call relationships are occurring among young adults. Since there is no research on long-distance booty call relationships, this could become a new area for future research not only on booty call relationships, but also friends with benefits relationships.

\section{I'm Just Not That Into You}

Most of the booty call relationships in this research study did not progress into a romantic dating relationship. This prompted me to ask the participants why their booty call did not turn into anything more serious, and there was a very collective answer: They were just not that into their partner. The participants shared how they just were not that interested in their booty call partner. This theme can be broken down into subthemes. 
Not a good person. Both men and women participants indicated that they did not want to enter a romantic dating relationship with their booty call partner because they did not view their partner as a good person. Ryder shared, “I also really didn't like her-as a person she just wasn't that nice” Coleen shared, “He just isn't a very good person. Even though he is beautiful, I would never take him home to meet my parents." Furthermore, Jackie also did not see her booty call partner as a good person as she shared, "I knew about his slutty reputation and like just knew he wasn't really a good person. I just knew he wouldn't be a good boyfriend." Maureen also shared, He was attractive and popular, and maybe if he was nice to me and was sweet to me, things might have developed differently, but he wasn't and I just wasn't interested in being a real relationship with him. He also had a bad reputation and I didn't want to be a part of that.

In sum, some participants did not view their booty call partner as a likeable person or with respect. However, when asked why the participants entered a booty call relationship with this specific partner, participants reported that they wanted to have some fun and they found their booty call partner to be attractive. Jonason et al. (2011) found that physical attractiveness played an important role in booty call relationships. Therefore, even though they found their booty call partner to be attractive, they did not view them as a good person.

Trust. Trust is a fundamental aspect in any healthy relationship. Interpersonal communication plays an important role in developing and 
maintaining trust between partners (Weber, Johnson \& Corrigan, 2004). In romantic and sexual relationships, trust plays a key role in promoting intimacy, forgiveness and willingness to sacrifice (Rusbult, Kumashiro, Coolsen, \& Kirchner, 2004). It has been shown throughout time that trust is a key factor in developing and maintaining relationships, whether family, friends, co-workers, or romantic relationships.

In this study, some participants shared that they did not trust their partner, which is another reason they did not want to enter a romantic relationship with their booty call partner. For example, Mary shared, “He isn't the type of person I would want to be in a serious relationship with. I mean if he is going to hook up with me, who else he is hooking up with?"

Steve shared, "She wasn't trustworthy, I mean we set the rule not to hook up with other people, but yet she was still making out with random people at the bars." In addition to that, Victor explained, "I don't know if I would date her because she would have to show me that I could trust her, because obviously I can't trust her at all if she is hooking up with me while she is in a relationship with another person."

Participants were willing to share how they did not want to enter a romantic relationship with their booty call partner because they did not see them as a good person or trustworthy; however, they failed to realize that they were also engaging in the same behaviors. In a sense, the participants saw themselves as victims or as innocent. They never discussed how they were 
behaving negatively, but were always discussing how their partner was not an ideal candidate for a romantic relationship.

\section{Setting The Script}

One of the few constants surrounding heterosexual courtship in the American culture is change, as each generation alters premarital romantic and sexual norms (Mongeau, Knight, Williams, Eden, \& Shaw, 2013). Today, sexual standards are more permissive and focus on non-traditional sexual relationships (Bogle, 2008). While research has focused on scripts for one-night stands and friend with benefit relationships, it has neglected the script for the booty call relationship.

The goal of this study was to try and identify the sexual script of the booty call relationship. However, it was found that each booty call relationship is very different; therefore, no universal sexual script can be set for the booty call relationship. The past literature on booty call relationships assumes that they are a singular relationship type; however, it has been found that there are different motivations for entering a booty call relationship. Instead, what researchers should now focus on is to try and identify the most common types of booty call relationships. It would be more beneficial to try to identify the most common types of booty call relationships to then help develop the script.

In this research, the different types of booty call relationships that were found include, long-distance booty call relationship, work-related booty call relationships, booty call relationship with strangers, and booty call 
relationships with acquaintances. Through doing more research, more concrete types of booty call relationships could be better developed and understood.

\section{Alcohol, Text Messages, and Emotions}

\section{Alcohol}

The participants were asked about the role of alcohol in each stage of their booty call relationship. It was no surprise that alcohol played a significant factor in the development and maintenance of the booty call relationship. As it has been stated earlier, research has indicated that alcohol plays a large factor in almost every non-traditional sexual relationship. However, it was surprising the amount of recreational marijuana used in the booty call relationship. Specifically, the participants shared how they would smoke marijuana before or after the hook up while they were hanging out. The most memorable time was when Victor shared, "We would hook up and after we would hookup, we would smoke a bowl. Then usually when we were high we would hook up again and then I would leave." Grant and MacDonald (2005) found that drugs rather than alcohol influenced $22 \%$ of hookups among college students.

\section{Text Messages}

One of the key features that distinguish booty calls from other nontraditional sexual relationships is the use of mobile technology to arrange a sexual encounter. To initiate a hook up in the booty call relationship, it requires some anticipation and planning (Jonason et al., 2010). In this research study, it was found that both men and women would utilize text messaging and Snapchat to initiate a hook up with their booty call partner. 
The use of texting and Snapchat, instead of making a phone call, to pursue a sexual hook up in the booty call relationship is relatively new phenomenon. As individuals become more technological savvy, these individuals rely more on texting to arrange a hookup. Instead of having direct, face-to-face conversation and having the fear of getting rejected by their booty call partner, individuals can protect their face and self-esteem by using texting to arrange the hookup.

It would be interesting to study individuals who are in multiple booty call relationships and see how they utilize text messaging to keep their booty call relationships organized and to initiate a hookup. I would assume that these individuals would have code names for each booty call partner, to not only keep them organized but to also keep them a secret from other individuals who are in a booty call relationship with that person. Furthermore, I would assume that these individuals would send out a mass text message to all their booty call partners to increase their chance of hooking up.

\section{Emotions}

In this research study, it was assumed that participants would express various emotions at each stage of the booty call relationship. With a few exceptions, research suggests that females' reactions to hookups tend to be negative, whereas males' reactions tend to be positive (Townsend \& Wasserman, 2011). However, in this research study, I found that the most common emotions associated with their booty call relationship were happiness and guilt. 
From past research, I was assuming that females would have expressed more negative emotions and males would express more positive emotions. While three females did state that the relationship made them feel anxious or jealous, it was not a commonality among all female participants. Furthermore, with the male participants none expressed a variety of emotions, rather they all only discussed a few basic emotions that they felt. In addition, a total of five partcipants, both male and female combined, expressed that they were emotionless throughout the whole relationship. As Elizabeth shared, "Honestly, there were no emotions at all during our relationship. I was surprised about how little emotions there were. We didn't hang out, we didn't have conversation, it was strictly like 'Hi. How are you?' then we would hook up and then he would leave. I mean, I was attracted to him physically but I had no desire to try to develop an emotional connection with him."

Justin also shared how he was emotionless the whole time, "I actually had no emotions about the relationship whatsoever. Like I knew she really didn't want to date me and I didn't really want to date her, so really I felt nothing for her."

In this study, there could be multiple reasons as to why there was a gap in the emotion results. Perhaps, the participants did not know how to verbalize the emotions they were experiencing, the relationship was too long ago so they forgot the emotions they did experience, or they did not want to admit they felt any emotions. In the future, it would be more beneficial to quantitatively 
measure emotions to fully understand the role of emotions in booty call relationships.

\section{Strengths, Limitations and Directions for Future Research}

\section{Strengths and Limitations}

This study has several important strengths. The findings highlight the benefit of using a qualitative approach to examine how participants developed, maintained, and terminated their booty call relationship. The themes developed were based on rich qualitative data, presented in the participant's own words, which helped their ability to accurately reflect on their own experiences and the complexity of the phenomena being studied.

The results should be considered in light of several limitations. First, some participants were currently engaged in the booty call relationship, so they could not explain why their relationship ended or concretely explain why they did not want to enter a romantic dating relationship with their partner since there was still a chance it would progress into a more committed traditional relationship.

On the other hand, some participants were asked to recall past events, behaviors, and feelings, which could have been distorted and reappraised into a more negative or positive valence. Selective self-monitoring of positive aspects and temporary distance from the experiences described may have impacted participant's recall of their booty call experiences (Downey, Ryan, Roffman, \& Kulich, 1995; Paul \& Hayes, 2002). 
Third, I did not interview both individuals in the dyad booty call relationship, which could have yielded different perceptions and experiences for each stage of the booty call relationship. In the future, booty call relationship research should include longitudinal and dyadic data collection. However, this can be difficult since each booty call relationship is initiated in different contexts. A combination of longitudinal, recall, and interview studies will likely yield the most accurate and fruitful data.

Future studies need to take into account the diverse ways that individuals define hookups as well as the ways they use the term in context. Individuals use the word, hookup, to ambiguously explain their sexual encounter, which can range from kissing to sexual intercourse. Research has shown that $98 \%$ of hookups involve kissing (Fielder \& Carey, 2010). In the context of a hookup, Reiber and Garcia (2010) found that $58 \%$ of individuals engaged in sexual touching above the waist, $53 \%$ below the waist, $36 \%$ performed oral sex, $35 \%$ received oral sex, and $34 \%$ engaged in sexual intercourse. Although the term hook up focuses on the uncommitted nature of the casual sexual encounter, many individuals place emphasis on the sexual behaviors used in a hook up (Reiber et al., 2012). Even though the understanding of the word "hookup" was clear among the participants in this study, it would be beneficial to understand the different contexts participants use hook up in their booty call relationships. For example, are participants engaging in oral sex, vaginal intercourse, or just kissing within their booty call relationship? 
Furthermore, this study should quantitatively collect data about the perceived role of alcohol, emotions, and text messages in the booty call relationship. It would be beneficial to conduct quantitative research that reflects the emerged themes from this study to produce greater measures of validity and reliability (Lindlof \& Taylor, 2011).

Finally, a female interviewer conducted each interview. Both male and female participants may have responded to some questions differently if a male interviewed them.

\section{Future Research}

In closing, there are a number of avenues for future research. To begin, there are many different directions for future research when it comes to looking at booty call relationships through the lens of communication. First, it is evident that there is not much verbal communication between the individuals in the booty call relationship. While they are communicating about logistics of the booty call hook up (e.g., where, when), they are not engaging in self-disclosure. Rather, they are more likely to avoid any type of relational communication with each other; therefore, it would be interesting to study the reasoning behind the avoidance of verbal communication. On the other hand, if the individual does self-disclose personal information to their boot call partner, it would be intriguing to study the role, frequency, and effect of self-disclosure within the booty call relationship.

Furthermore, scholars could investigate how the individuals communicate about their expectations for the booty call relationship. While it 
was not a direct focus for this study, it would be important to research whether, and how, individuals explicitly or implicitly talk about their expectations from the relationship. In addition, if expectations are communicated, how do these affect the dynamic of the relationship if the expectations are similar or different between the two individuals?

The participants in this study were asked about whether they established any ground rules about the relationship. While it was not a common theme among participants to explicitly establish ground rules, when they did establish ground rules, it was to keep the relationship a secret. As Gina stated, "I didn't want the world to know that I was a in a booty call relationship and [be] judging me for it, so I told him that we had to keep our relationships a secret." From this, it would fascinating to research further the motivation behind keeping the booty call relationship a secret from their social networks. Furthermore, if the relationships are not kept a secret, how do the individuals communicate with their social networks about their booty call relationship to their social networks? Finally, how individuals discuss his or her past booty call relationships with his or her future traditional romantic partner and the effect it has on that relationship.

The next major direction for future research would to try and reach a better understanding of the motivation behind booty call relationships could lead to beneficial research about booty call relationships as whole. In this study, the participants were asked why they entered a booty call relationship and why they entered a booty call relationship with their specific partner. The 
most common answers among participants were: 1) just to have fun, 2) had recently gotten out of a serious relationship, or 3) it was not planned. While research has found the motivational reasoning in developing a friends with benefits relationship (Bisson \& Levine, 2009; Epstein et al., 2009; Owen \& Fincham, 2010) or engaging in a one night stand (Bradshaw et al., 2010; Grello et al., 2006; Paul et al., 2000), more data are needed to learn the motivation behind men and women entering a booty call relationship.

Another direction of interest would be researching same-sex booty call relationships. While this study only focused on heterosexual booty call relationships, it would be interesting to interview homosexuals to see if these individuals have similar or differing experiences. While a few researchers (Prestage, Jin, Grulich, de Wit, \& Zablotska, 2012; van den Boom, Stolte, Sandfortb, \& Davidovicha, 2012) have explored same sex casual sexual relationships, there has not been a targeted investigation of associations between sexual orientation and booty call relationships

A third future direction would be examining the dark side of booty call relationships. Deception could be prevalent in each stage of the booty call relationship. It would be useful to focus on how individuals utilize deception to develop, maintain and terminate their booty call relationships. Thereafter, since casual sexual relationships can have a negative effect on the psychological well-being of an individual (Amato et al., 2008), it would be interesting to study how booty call relationships do affect the development of future romantic relationships. 


\section{Summary}

In conclusion, I have examined a type of non-traditional sexual relationship that is starting to gather more interest in the sex communication area. In doing so, I have attempted to identify the sexual script of the booty call relationship. While I was not able to identify a universal sexual script, I was able to conclude that there are different types of booty call relationships,

thus leading to future research. Furthermore, I researched the role of alcohol, text messages, and emotions in the booty call relationship. 


\section{REFERENCES}

Afifi, W., \& Faulkner, S. L. (2000). On being 'just friends': The frequency and impact of sexual activity in cross-sex friendships. Journal of Social and Personal Relationships, 17, 205-222. doi: 10.1177/0265407500172003

Amato, P., Lansdale, N., Havasevich-Brooks, T., Booth, A., Eggebeen, D., Schoen, R., \& McHale, S. M. (2008). Precursors of young women's family formation pathways. Journal of Marriage and Family, 70, 1271-1286. doi: $10.1111 / \mathrm{j} .1741-3737.2008 .00565 . x$

Backstrom, L., Armstrong, E., \& Puentes, J. (2012). Women's negotiation of cunnilingus in college hookups and relationships. Journal of Sex Research, 49, 1-12. doi: 10.1080/00224499.2011.585523

Baldwin, M. (1992). Relational schemas and the processing of social information. Psychological Bulletin, 112, 461-484.

Banker, J., Kaestle, C., \& Allen, K. (2010). Dating is hard work: A narrative approach to understanding sexual and romantic relationships in young adulthood. Comtemporary Family Therapy, 32, 173-191. doi: 10/1007/s10591-009-9111-9

Barrett, L. (2006). Are emotions natural kinds? Perspectives on Psychological Science, 1, 29-46. doi: 10.1111/j.1745-6916.2006.00003.x

Barriger, M., \& Velez-Blasini, C., (2013). Descriptive and injunctive social norm overestimation in hooking up and their role as predictors of hookup activity in college study sample. Journal of Sex Research, 50, 84-94. doi: 10.1080/00224499.2011.6079

Batson, C., Shaw, L., \& Oleson, K. (1992). Differentiating affect, mood, and emotion: Toward functionally based conceptual distinctions. In M. S. Clark (Ed.), Review of personality and social psychology, Vol. 13: Emotion (pp. 294-326). Newbury Park, CA: Sage.

Baxter, L. (1991). Content analysis. In B. M. Montgomery \& S. Duck (Eds.), Studying interpersonal communication (pp. 239-254). New York, NY: Guilford Press. 
Bernard, R. (1988). Research methods in cultural anthropology. Newbury Park, CA: Sage.

Bersamin, M., Paschall, M., Saltz, R., \& Zamboanga, B. (2012). Young adults and casual sex: The relevance of college drinking settings. Journal of Sex Research, 49, 274-281. doi: 10.1080/00224499.2010.548012

Bevan, J., \& Hale, J. (2006). Negative jealously related emotion rumination as consequences of romantic partner, cross-sex friend, and sibling jealously expression. Communication Studies, 4, 363-379. doi:10.1080/10510970600945907

Bisson, M., \& Levine, T. (2009). Negotiating a friends with benefits relationship. Archive of Sex Behaviors, 38, 66-73. doi 10.1007/s10508007-9211-2

Bogle, K. (2007). The shift from dating to hooking up in college: What scholars have missed. Sociology Compass, 1, 775-788. doi: 10.1111/j.17519020.2007.00031.x

Bogle, K. (2008). Hooking up: Sex, dating, and relationships on campus. New York, NY: New York University Press.

Borae J., \& Pena, J (2010). Mobile communication in romantic relationships: Mobile phone use, relational uncertainty, love, commitment, and attachment styles. Communication Reports, 23, 39-51. doi: $10.1080 / 08934211003598742$

Bowleg, L., Lucas, K., \& Tschann, J. (2004). "The ball was always in his court": An exploratory analysis of relationships scripts, sexual scripts, and condom use among African American women. Psychology of Women Quarterly, 28, 70-82. doi: 10.1111/j.1471-6402.2004.00124.x

Bradshaw, C., Kahn, A., \& Saville, B. (2010). To hookup or date: Which gender benefits? Sex Roles, 62, 661-669. doi:10.1007/s11199- 010-9765-7

Braun, V., \& Clarke, V. (2006). Using thematic analysis in psychology. Qualitative Research in Psychology, 3, 77-101. doi: 10.1191/1478088706qp063oa

Buss, D. (1989). Conflict between the sexes: Strategic interference and the evocation of anger and upset. Journal of Personality and Social Psychology, 56, 735-747. 
Buss, D., \& Schmitt, D. (1993). Sexual strategies theory: An evolutionary perspective on human mating. Psychological Review, 100, 204-232.

Campbell, A. (2008). The morning after the night before: Affective reactions to one night stands among mated and unmated women and men. Human Nature, 19, 157-173. doi: 10.1007/s12110-008-9036-2

Chia, S., \& Gunther, A. (2006). How media contribute to misperceptions of social norms about sex. Mass Communication \& Society, 9, 301-320. doi:10.1207/s15327825mcs0903_3

Chng, C., \& Moore, A. (1994). AIDS: Its effects on sexual practices among homosexual and heterosexual college students. Journal of Health Education, 25, 154-160. doi: 10.1080/10556699.1994.10603030

Cohen, L., \& Shotland, R. (1996). Timing of first sexual intercourse in a relationship: Expectation, experiences, and perceptions of others. Journal of Sex Research, 33, 291-299. doi: 10.1080/00224499609551846

Coleman, J. (1988). Intimate relationships, marriage, and family (2nd ed.). New York, NY: MacMillan.

Collins, W., \& van Dulmen, M. (2006). Friendships and romance in emerging adulthood: Assessing distinctiveness in close relationships. In J. J. Arnett $\&$ J. L. Tanner (Eds.), Emerging adults in America: Coming of age in the 21st century (pp. 219-234). Washington, DC: American Psychological Association.

Cooper, M. (2002). Alcohol use and risky sexual behavior among college students and youth: Evaluating the evidence. Journal of Studies on Alcohol, 14, 101-117.

Crawford, M., \& Popp, D. (2003). Sexual double standards: A review and methodological critique of two decades of research. Journal of Sex Research, 40, 13-26. doi:10.1080/00224490309552163

Creswell, J. (2007). Qualitative inquiry \& research design: Choosing among five approaches (2nd ed.). Thousand Oaks, CA: Sage.

Cupach, W., \& Metts, S. (1992). The effects of type of predicament and embarrassability on remedial responses to embarrassing situations. Communication Quarterly, 40, 149-161. doi: $10.1080 / 01463379209369830$ 
Downey, L., Ryan, R., Roffman, R., \& Kulich, M. (1995). How could I forget? Inaccurate memories of sexually intimate moments. The Journal of Sex Research, 32, 177-191. doi: 10.1080/00224499509551789

Duck, S., West, L., \& Acitelli, L. K. (1997). Sewing the field: The tapestry of relationships in life and research. In S. Duck (Ed.), Handbook of personal relationships: Theory, research and interventions (pp. 1-28). New York, NY: John Wiley \& Sons.

Eisenberg, M., Ackard, D., Resnick, M., \& Neumark-Sztainer, D. (2009). Casual sex and psychological health among young adults: Is having causal sex emotionally damaging? Perspectives on Sexual Reproductive Health, 41, 231-237. doi: 10.1363/4123109

Edelmann, R. (1985). Social embarrassment: An analysis of the process. Journal of Social and Personal Relationships, 2, 195-213. doi: $10.1177 / 0265407585022006$

Emmott, C., \& Alexander, M. (2011). "Schemata." In H. Peter et al. (Eds.), The living handbook of narratology. Hamburg: Hamburg University Press. Retreived from: hup.sub.uni-hamburg.de/lhn/index.php?title=Schemata Eoldid=1075

Epstein, M., Calzo, J., Smiler, A., \& Ward, L. M. (2009). 'Anything from making out to having sex': Men's negotiations of hooking up and friends with benefits scripts. Journal of Sex Research, 46, 414-424. doi: $10.1080 / 00224490902775801$

Eshbaugh, E., \& Gute, G. (2008). Hookup and sexual regret among college women. Journal of Social Psychology, 148, 77-89. doi: 10.3200/SOCP.148.1.77-90

Fehr, B., Baldwin, M., Collins, L., Patterson, S., \& Benditt, R. (1999). Anger in close relationships: An interpersonal script analysis. Personality and Social Psychology Bulletin, 3, 299-312. doi: 10.1177/0146167299025003003

Fielder, R., \& Carey, M. (2010). Prevalence and characteristics of sexual hookups among first-semester female college students. Journal of Sex \& Marital Therapy, 36, 346-359. doi: 10.1080/0092623X.2010.488118

Filner, L. (2007). Trends in premarital sex in the United States 1954-2003. Public Health Reports, 122, 73-78. doi: 10.1080/01494929.2013.879552 
Fisher, M., Worth, K., Garcia, J., \& Meredith, T. (2012). Feelings of regret following uncommitted sexual encounters in Canadian university students. Culture, Health \& Sexuality, 14, 45-57. doi: 10.1080/ 13691058.2011.61957

Fisher, W. (1987). Human communication as narration: Toward a philosophy of reason, value, and action. Columbia, SC: University of South Carolina Press.

Fletcher, G. (1993). Cognition in close relationships. New Zealand Journal of Pscyhology, 22, 69-81. doi: 10.1080/02699938708408364

France, B. (2010). What verbal and nonverbal communication cues lead to sex?: An analysis of the traditional sexual script. Communication Quarterly, 58, 297-318. doi: 10.1080/01463373.2010.503161

Fredrickson, B. (1998). What good are positive emotions? Review of General Psychology, 2, 300-319. doi: 10.1037/1089-2680.2.3.300

Fredrickson, B. (2001). The role of positive emotions in positive psychology: The broaden-and-build theory of positive emotions. American Psychologist, 56, 218-226. doi: 10.1037//0003-066X.56.3.218

Fredrickson, B., \& Branigan, C. (2005). Positive emotions broaden the scope of attention and thought-action repertories. Cognition and Emotion, 19, 313-332. doi: 10.1080/02699930441000238

Furman, W., \& Shaffer, L. (2011). Romantic partners, friends with benefits, and casual acquaintances as sexual partners. Journal of Sex Research, 48, 554-564. doi: 10.1080/00224499.2010.535623

Garcia, J., \& Reiber, C. (2008). Hookup behavior: A biopsychosocial perspective. The Journal of Social, Evolutionary, and Cultural Psychology, 2, 192-208. doi: 10.1037/h0099345

Garcia, J., Reiber, C., Massey, S., \& Merriwether, A. (2012). Sexual hookup culture: A review. Review of General Psychology, 16, 161-176. doi: $0.1037 / \mathrm{a} 0027911$

Garcia-Montes, J., Caballero-Munoz, D., \& Perez-Alvarez, M. (2006). Changes in the self resulting from the use of mobile phones. Media, Culture, \& Society, 28, 67-82. doi: 10.1177/0163443706059287 
Gentzler, A. (2004). Associations between insecure attachment and sexual experiences. Personal Relationships, 11, 249-265. doi: 10.1111/j.14756811.2004.00081

Gilbert, G., Clark, M., \& Anderson, M. (2012). Do deaf individuals' dating scripts follow the traditional sexual script? Sexuality \& Culture, 16, 9099. doi: 10.1007/s12119-011-9111-4

Gilbert, P. (2003). Evolution, social roles, and the differences in shame and guilt. Social Research, 70, 1205-1230. doi: 10.1111/j.20448341.1997.tb01893.x

Gilmartin, S. (2006). Changes in college women's attitudes toward sexual intimacy. Journal of Research on Adolescence, 16, 429-454. doi: $10.1111 /$ j.1532-7795.2006.00501.x

Glenn, N., \& Marquardt, E. (2001). Hooking up, hanging out, and hoping for Mr. Right: College women on dating and mating today. New York, NY: Institute for American Values.

Goa, J., Wang, A., \& Qian, M. (2010). Differentiating shame and guilt from a relational perspective: A cross-cultural study. Social Behavior and Personality, 38, 1401-1408. doi: 10.2224/sbp.2010.38.10.1401

Goffman, E. (1956). Embarrassment and social organization. American Journal of Sociology, 62, 264-271.

Goffman, E. (1967). Interaction ritual: Essays on face-to-face behavior. Garden City, NJ: Anchor.

Gold, R., Karmiloff-Smith, A., Skinner, M., \& Morton, J. (1992). Situational factors and thought processes associated with unprotected intercourse in heterosexual students. AIDS Care, 5, 305-323. doi: $10.1080 / 09540129208253101$

Grant, N., \& MacDonald. T. (2005). Can alcohol lead to inhibition or disinhibition? Alcohol and Alcoholism, 40, 373-378. doi: 10.1093/alcalc/agh177

Green, K., \& Sandos, P. (1983). Perceptions of male and female initiators of relationships. Sex Roles, 9, 849-852. doi: 10.1007/BF00289958

Grello, C., Welsh, D., \& Harper, M. (2006). No strings attached: The nature of casual sexing college students. Journal of Sex Research, 43, 255-267. doi: $10.1080 / 00224490609552324$ 
Grello, C., Welsh, D., Harper, M., \& Dickson, J. (2003). Dating and sexual relationships trajectories and adolescent functioning. Adolescent and Family Health, 3, 103-112.

Hareli, S., \& Parkinson, B. (2008). What's social about social emotions? Journal for the Theory of Social Behavior, 21, 131-156. doi: 10.1111/j.14685914.2008.00363.x

Hartz, L., de Rivera, J., Mascolo, J., \& Tangney, M. (1995). Differentiating guilt and shame and their effects on motivation. In J. Price \& K. Fischer (Eds), Self-conscious emotions: The psychology of shame, guilty, embarrassment, and pride (pp. 274-300). New York, NY: Guilford Press

Haselton, M., \& Buss, D. (2001). The affective shift hypothesis: The functions of emotional changes following sexual intercourse. Personal Relationships, 8, 357-369. doi: $10.1111 /$ j.1475-6811.2001.tb00045

Hatfield, E., Hutchison, E. S. S., Bensman, L., Young, D. M., \& Rapson, R. L. (in press). Cultural, social, and gender influences on casual sex: New developments. In Jan M. Turner \& Andrew D. Mitchell (Eds.), Social psychology: New developments. Hauppauge, NY: Nova Science.

Hayes, J., \& Metts, S. (2008). Managing the expression of emotion. Western Journal of Communication, 72, 374-396. doi: $10.1080 / 10570310802446031$

Holmberg, D., \& Blair, K. (2009). Sexual desire, communication satisfaction, and preferences of men and women in same-sex versus mixed-sex relationships. Journal of Sex Research, 46, 57-66. doi: $10.1080 / 00224490802645294$

Honeycutt, M., \& Cantrill, G. (2000). Cognition, communication, and romantic relationships. Mahwah, $\mathrm{NJ}$ : Erlbaum.

Horan, S., \& Dillow, M. (2009). Deceivers and emotion: The relationships among deceptive message type, relational qualities, and guilt and shame. Atlantic Journal of Communication, 17, 149-165. doi: $10.1080 / 15456870903156126$

Hynie, M., Lydon, J., Cote, S., \& Wiener, S. (1998). Relational sexual scripts and women's condom use: The importance of internalized norms. Journal of Sex Research, 35, 370- 380. doi: 10.1080/00224499809551955 
Impett, E., \& Peplau, L. (2003). Sexual compliance: Gender, motivational, and relationship perspectives. Journal of Sex Research, 40, 87-100. doi: $10.1080 / 00224490309552169$

Jackson, P., Kleiner, S., Geist, C., \& Cebulko, K. (2011). Conventions of courtship: Gender and race differences in the significance of dating rituals. Journal of Family Issues, 32, 629-652. doi: $10.1177 / 0192513 \times 10395113$

Jonason, P., Li, N., \& Cason, M. (2009). The "booty call": A compromise between men's and women's ideal mating strategies. Journal of Sex Research, 46, 460-470. doi: 10.1080/00224490902775827

Jonson, P., Li, N., \& Richardson, J. (2010). Positioning the relationships on the spectrum of relationships: Sexual but more emotional than the one-night stands. Journal of Sex Research, 47, 1-10. doi: 10.1080/00224499.2010.497984

Kalish, R., \& Kimmel, M. (2011). Hooking up: Hot hetero sex or the new numb normative? Australian Feminist Studies, 26, 137-151. doi: 10.1080/08164649.2011.546333

Klinkenberg, D., \& Rose, S. (1994). Dating scripts of gay men and lesbians. Journal of Homosexuality, 26, 23-25. doi: 10.1300/J082v26n04_02

Koerner, A. (2009). Family and marital schemas and types. In S. Littlejohn \& K. Foss (Eds.), Encyclopedia of communication theory. (pp. 378-382). Thousand Oaks, CA: Sage. doi: 10.4135/9781412959384.n141

Knobloch, L., \& Metts, S. (2013). Emotion in relationships. In J. A. Simpson \& L. Campbell (Eds.), The Oxford handbook of close relationships (pp. 514534). New York, NY: Oxford University Press.

LaPlante, M., McCormick, N., \& Brannigan, G. (1980). Living the sexual script: College students' views of influence in sexual encounters. The Journal of Sex Research, 16, 338-355. doi: 10.1080/00224498009551090

Laner, M., \& Ventrone, N. (2000). Dating scripts revisited. Journal of Family Issues, 21, 488- 500. doi: 10.1177/019251300021004004

Laumann, E., Paik. A., Glasser, D., Kang, J., Wang, T., \& Levinson, B. (2006). A cross-national study of subjective sexual well-being among older women and men: Findings from the global study of sexual attitudes and behaviors. Archives of Sexual Behavior, 35, 145-161. doi: 10.1007/s10508-005-9005-3 
Lenhart, A. (2010). Teens, cell phones, and texting. Pew Internet and American Life Project. Retrieved from http://pewresearch.org/pubs/1572/teenscell-phones-text-messages

Lewis, M. (1992). Shame: The exposed self. New York, NY: The Free Press.

Lewis, M., Granato, H., Blayney, J., Lostutter, T., \& Kilmer, J. (2011). Predictors of hooking up sexual behavior and emotional reactions among U.S. college students. Archives of Sexual Behavior, 41, 1219-1229. doi: 10.1007/s10508-011-9817-2

Li, N., \& Kenrick, D. (2006). Sex similarities and differences in preferences for short-term mates- what, whether, and why. Journal of Personality and Social Psychology, 90, 468-489. doi: 10.1037/0022-3514.90.3.468

Lincoln, Y., \& Guba, E. (1985). Naturalistic inquiry. Beverly Hills, CA: Sage.

Lindlof, T., \& Taylor, B. (2011). Qualitative communication research methods ( $3^{\text {rd }}$ ed.). Thousand Oaks, CA: Sage.

Littleton, H., \& Axsom, D. (2003). Rape and seduction scripts of university students: Implications for rape attributions and unacknowledged rape. Sex Roles, 49, 465-475. doi:10.1023/A:1025824505185

Manning, W., Giordano, P., \& Longmore, M. (2006). Hooking up: The relationships contexts of "nonrelationship" sex. Journal of Adolescent Research, 21, 459-483. doi: 10.1177/0743558406291692

Manning, W., Longmore, M., \& Giordano, P. (2000). The relationship context of con- traceptive use at first intercourse. Family Planning Perspectives, 32, 104-110.

Manning, W., Longmore, M., \& Giordando, P. (2005). Adolescents' involvement in non-romantic sexual activity. Social Science Research, 34, 384-407. doi: 10.1016/j.ssresearch.2004.03.001

Markus, H. (1977). Self-schemata and processing information about the self. Journal of Personality and Social Psychology, 35, 63-78. doi: 10.1037/0022-3514.35.2.63

Masters, T., Casey, E., Wells, E., \& Morrison, D. (2013). Sexual scripts among young heterosexually active men and women: Continuity and change. Journal of Sex Research, 50, 409-420. doi: 10.1080/00224499.2012.661102 
McGinty, K., Knox, D., \& Zusman, M. (2007). Friends with benefits: Women want "friends," men want "benefits." College Student Journal, 41, 1128-1131.

Meilman, P. (1993). Alcohol induced sexual behavior on campus. Journal of American College Health, 42, 27-31. doi:

$10.1080 / 07448481.1993 .9940453$

Metts, (In Press). Sexual communication. In C. Berger (Ed.), International Encyclopedia of Interpersonal Communication, 1-4. New York, NY: John Wiley \& Sons.

Metts, S., \& Spitzberg, B. (1996). Sexual communication in interpersonal contexts: A script based approach. In B. R. Burleson \& A. W. Kunkel (Eds.), Communication yearbook 19 (pp. 49-91). Thousand Oaks, CA: Sage.

Milhausen, R., \& Herold, E. (1999). Does the sexual double standard still exist? Perceptions of university women. Journal of Sex Research, 36, 361-368. doi: $10.1080 / 0022449990955200$

Miller, K. (2005). Communication theories: Perspectives, processes, and contexts ( $2^{\text {nd }}$ ed. $)$. Boston: McGraw-Hill.

Miller, R. (1996). Embarrassment: Poise and peril in everyday life. New York, NY: Guilford.

Mitchell, K., Wellings, K., Nazareth, I., King, M., Mercer, C., \& Johnson, A. (2011). Scripting sexual function: A qualitative investigation. Sociology of Health \& Illness, 33, 540-553. doi: 10.1111/j.1467-9566.2011.01318.x

Mongeau, P., Jacobsen, J., \& Donnerstein, C. (2007). Defining dates and first date goals: Generalizing from undergraduates to single adults. Communication Research, 34, 526-547. doi: 10.1177/0093650207305235

Mongeau, P., Knight, K., Williams, J., Eden, J., \& Shaw, C. (2013). Identifying and explicating variation among friends with benefits relationships. Journal of Sex Research, 50, 37-47. doi: 10.1080/00224499.2011.623797

Morr, M., \& Mongeau, P. (2004). First-date expectations: The impact of sex of initiator, alcohol consumption, and relationship type. Communication Research, 31, 3-35. doi: 10.1177/0093650203260202 
Nishida, H. (2005). Cultural schema theory. In W. B. Gudykunst (Ed.), Theorizing about intercultural communication (pp. 401-418). Thousand Oaks, CA: Sage Publications.

Oliver, M., \& Hyde, J. (1993). Gender differences in sexuality: A meta-analysis. Psychological Bulletin, 114, 29-51. doi:10.1037//0033-2909.114.1.29.

Ostrager, B. (2010). SMS. OMG! LOL! TTYL: Translating the law to accommodate today's teens and the evolution from texting to sexting. Family Court Review, 48, 712-726. doi: 10.1111/j.17441617.2010.01345.x

Owen, J., \& Fincham, F. (2011). Young adults' emotional reactions after hooking up encounters. Archives of Sexual Behavior, 40, 321-330. doi: 10.1007/s10508-010-9652-x

Owen, J., Fincham, F., \& Moore, J. (2011). Short-term perspective study of hooking up among college students. Archives of Sexual Behavior, 40, 331-341. doi: 10.1007/s10508-010-9697-x

Owen, J., \& Fincham, F. (2012). Friends with benefits relationships as a start to exclusive romantic relationships. Journal of Social and Personal Relationships 29, 983-996. doi: 10.1177/0265407512448275

Owen, J., Rhoades, G., Stanley, S., \& Fincham, F. (2010). “Hooking up” among college students: Demographics and psychosocial correlates. Archives of Sexual Behavior, 39, 653-663. doi: 10.1007/s10508-008-9414-1

Paul, E. (2006). Beer goggles, catching feelings, and the walk of shame: The myths and realities of the hookup experience. In D. Kirkpatrick, S. Duck, M. Foley (Eds.), Relating difficulty: The processes of constructing and managing difficult interaction. Mahwah, NJ: Lawrence Erlbaum.’

Paul, E. , \& Hayes, K. (2002). The casualties of "casual” sex: A qualitative exploration of the phenomenology of college students' hookups. Journal of Social and Personal Relationships, 19, 639-661. doi:

10.1177/0265407502195006

Paul, E., McManus, B., \& Hayes, K. (2000). "Hookups": Characteristics and correlates of college students' spontaneous and anonymous sexual experiences. Journal of Sex Research, 37, 76-88. doi:

$10.1080 / 00224490009552023$ 
Paul, E., Wenzel, A., \& Harvey, J. (2008). Hookups: A facilitator or a barrier to relationship initiation and intimacy development? In S. Sprecher, A. Wenzel, \& J. Harvey (Eds.), Handbook of relationship initiation (pp. 375-390). New York, NY: Taylor and Francis.

Pettigrew, J. (2009). Text messaging and connectedness within close interpersonal relationships. Marriage and Family Review, 45, 697-716. doi: 10.10.80/01494920903224268

Piotrowski, C., \& Kass, S. (2013). The scope of cell phone research in psychological literature. Psychology and Education: An Interdisciplinary Journal, 50, 29-32. doi: 10.1180/0147492903224268

Pistole, C., \& Roberts, A. (2011). Measuring long-distance romantic relationships: A validity study. Counseling and Development, 44, 63-76. doi: $10.1177 / 074817561140028$

Prestage, G., Jin, F., Grulich, A., de Wit, J., \& Zablotska, I. (2012). Gay men are less likely to use condoms with casual sex partners they know 'well.' AIDS \& Behavior, 16, 664-668. doi: 10.1007/s10461-011-9952-8

Pryor, J., \& Merluzzi, T. (1985). The role of expertise in processing social interaction script. Journal of Experimental Social Psychology, 21, 362379. doi: 10.1016/0022-1031(85)90036-8

Raley, R., Criseey, S., \& Muller, C. (2007). Of sex and romance: Late adolescent relationships and young adult union formation. Journal of Marriage and Family, 69, 1210-1226. doi: 10.1111/j.17413737.2007.00442.x

Reiber, C., \& Garcia, J. (2010). Hooking up: Gender differences, evolution, and pluralistic ignorance. Evolutionary Psychology, 8, 390-404. doi: $10.1080 / 00224490309552174$

Rivers, S., Brackett, M., Kataulak, N., \& Salovey, P. (2007). Regulating anger and sadness: An exploration of discrete emotions in emotion regulation. Journal of Happiness Studies, 8, 393-427. doi: 10.1007/s10902-006-90172

Rodriguez, M., Fischer, P., Manstead, A., \& Antony R. (2008). Attack, disapproval, or withdrawal? The role of honor in anger and shame responses to being insulted. Cognition and Emotion, 8, 1471-1498. doi: $10.1080 / 02699930701822272$ 
Roelofs, K., Putman, P., Schouten, S., Lange, W., Volman, I., \& Rinck, M. (2010). Gaze direction differentially affects avoidance tendencies to happy and angry faces in socially anxious individuals. Behavior Research and Therapy, 48, 290-294. doi: S0005796709002691

Rose, S., \& Frieze, I. (1993). Young singles' contemporary dating scripts. Sex Roles, 28, 499-509. doi: 10.1007/BF00289677

Roseman, I. (2001). A model of appraisal in the emotion system: Integrating theory, research, and applications. In K. R. Scherer, A. Schorr, \& T. Johnstone (Eds.), Appraisal processes in emotion: Theory, methods, research (pp. 68-91). Oxford, UK: Oxford University Press.

Rusbult, C., Kumashiro, M., Coolsen, M., \& Kirchern, J. (2004). Interdependence closeness, and relationships. In D. J. Mashek \& A. Aron (Eds.). Handbook of closeness and intimacy (pp. 137-161). Mahwah, NJ: Erlbaum.

Saffrey, C., Summerville, A., \& Roese, N. (2008). Praise for regret: People value regret above other negative emotions. Motivational Emotions, 32, 46-54. doi: 10.1007/s11031-008-9082-4

Sandberg-Thomas, S., \& Kamp Dush, C. (2014). Casual sexual relationships and mental health in adolescence and emerging adulthood. Journal of Sex Research, 51, 121-130. doi: 10.1080/00224499.2013.821440

Serewicz, M., \& Gale, E. (2008). First-date scripts: Gender roles, context, and relationship. Sex Roles, 58, 149-164. doi: 10.1007/s11199-007-9283-4

Simon, W., \& Gagnon, H. (1986). Sexual scripts: Permanence and change. Archives of Sexual Behavior 15, 97-120. doi: 10.1007/BF01542219

Simpson, J. (1987). The dissolution of romantic relationships: Factors involved in relationship stability and emotional distress. Journal of Personality and Social Psychology, 53, 683-692. doi: 10.1037/0022-3514.53.4.683

Sprecher, S., \& Metts, S. (2013). Logging on, hooking up: The changing nature of romantic relationship initiation and romantic relating. In C. Hazan \& M. Campa (Ed.), Human bonding (pp. 197-225). New York, NY: Guilford Press.

Stafford, L. (2004). Romantic and parent-child relationships at a distance. In P. Kalbfleisch (Ed.), Communication Yearbook 28 (pp.37-85). New Brunswick, NJ: International Communication Association. 
Stanglin, D. (2009, November 17). 'Unfriend' is New Oxford dictionary's Word of the Year. USA Today. Retrieved March 28, 2014, from http://content.usatoday.com/communities/ondeadline/post/2009/11/u nfriend-is-new-oxford-dictionarys-word-of-the-year-/1\#.U0tnCeZdWqw

Stockwell, P. (2006). "Schema theory: Stylistic applications.” In K. Brown (Ed.), Encyclopedia of language and linguistics (pp. 8-73). New York, NY: Oxford University Press.

Srivastava, L. (2005). Mobile phones and the evolution of social behavior. Behavior and Information Technology, 24, 111-129. doi: 10.1080/0144929051233132910

Suvivuo, P., Tossavainen, K., \& Kontula, O. (2010). "Can there be such a delightful feeling as this?" Variations of sexual scripts in Finnish girls' narratives. Journal of Adolescent Research, 25, 669-689. doi: $10.1177 / 0743558410366597$

Symonds, D. (1979). The evolution of human sexuality. New York, NY: Oxford University Press.

Townsend, J. M. (1995). Sex without emotional involvement: An evolutionary interpretation of sex differences. Archives of Sexual Behavior, 24, 173206. doi: $10.1007 / \mathrm{BF} 01541580$

Townsend, J. (1998). What women want-What men want. New York, NY: Oxford University Press.

Townsend, J., Kline, J., \& Wasserman, T. (1995). Low-investment copulation: Sex differences in motivations and emotional reactions. Ethology and Sociobiology, 16, 25-51. doi: 10.1016/0162-3095(94)00027-5

Townsend, J., \& Wasserman, T. (2011). Sexual hookups among college students: Sex differences in emotional reactions. Archives of Sexual Behavior, 40, 1173-1181. doi: 10.1007/s10508 011-9841-2

Tracy, J., \& Robins R. (2004). Putting the self into self-conscious emotions: A theoretical model. Psychological Inquiry, 15, 103-125. doi: 10.1207/s15327965pli1502_01

Tulane, S., \& Beckert, T. (2013). Perceptions of texting: A comparison of female high school and college students. North American Journal of Psychology, 15, 395-404. 
Weaver, S., \& Herold, E. (2000). Casual sex and women: Measurement and motivational issues. Journal of Psychology and Human Sexuality, 12, 2341. doi: 10.1300/J056v12n03_02

Weber, K., Johnson, A and Corrigan, M. (2004). Communicating emotional support and its relationship to feelings of being understood, trust and self-disclosure. Communication Research Reports, 21, 316-323. doi: 10.1080/08824090409359994

Wentland, J., \& Reissing, E. (2011). Taking casual sex not too casually: Exploring definitions of casual sexual relationships. The Canadian Journal of Human Sexuality, 20, 75-91.

Wicks, R. (1992). Schema theory and measurement in mass communication research: Theoretical and methodological issues in news information processing. In S. A. Deetz (Ed.), Communication Yearbook 15 (pp.115145). New Brunswick, NJ: International Communication Association.

Vander Ven, T., \& Beck, J. (2009). Getting drunk and hooking up: An exploratory study of the relationship between alcohol intoxication and casual couplings in a university sample. Sociological Spectrum, 29, 626648. doi: $10.1080 / 00224499.2011 .637246$

van den Boom, W., Stoltea, I., Sandfortb, T., \& Davidovicha, U. (2012). Serosorting and sexual risk behaviour according to different casual partnership types among MSM: The study of one-night stands and sex buddies. AIDS CARE, 24, 167-173. doi: 10.1080/09540121.2011.603285

Zammuner, V. L. (1996). Felt emotions, and verbally communicated emotions: The case of pride. European Journal of Social Psychology, 26, 233-245. doi: 10.1002/(SICl)1099-0992(199603)26:2<233::AID-EJSP748>3.0.CO;2-\#

Zisowitz, C. (1993). "Sadness is there such a thing?" In M. Lewis, \& J. Haviland (Eds.), Handbook of emotions (pp. 607-622). New York, NY: Guilford Press. 
APPENDIX A

EMAIL MESSAGE/FACEBOOK MESSAGE

TO PROSPECTIVE PARTICIPANTS

Dear Prospective Participant,

As a graduate student in the School of Communication at Illinois State University, I'm conducting a qualitative study about the script for booty call relationships under the guidance of Dr. John Baldwin as part of my Master's Thesis. A booty call relationship is a subset of non-traditional consensual sexual relationships, and it is defined as "the solicitation of a non-long term partner for explicit or implicit intent of engaging in sexual activity" (Jonason, Li, \& Cason, 2009, p. 460). With the booty call relationship being very prevalent with young adults on college campuses, this is a vital area to study. I would greatly appreciate your participation in this study.

In order to participate in this study, you must be at least 18 years of age or older and be currently in/have had a booty call relationship. If you choose to participate in this study, please contact Kayla using the information provided below to suggest a meeting location and time. This interview is expected to last between 30-60 minutes. This interview will ask you to respond to a series of questions relating to the development, maintenance, and termination of your booty call relationship.

Your participation is completely voluntary, and anything you answer during the interview will remain completely confidential. There is no penalty for choosing not to participate in this study. Furthermore, you have the right to decline to answer any question or withdraw from the study at any time without penalty or adversely affecting your relationship with Kayla, Dr. Baldwin, or Illinois State University.

To move forward with participating in this study, please contact Kayla Lucht by phone at 402-760-1365, or by email at kmlucht@ilstu.edu

Thank you for your consideration. 


\section{APPENDIX B \\ INFORMED CONSENT}

\section{Dear Student,}

I am a graduate student under the direction of Dr. John Baldwin in the School of Communication at Illinois State University. I am conducting a research study to understand the sexual script about the booty call relationship as part of a Master's Thesis.

A booty call relationship is a subset of non-traditional consensual sexual relationships, and it is defined as "the solicitation of a non-long term partner for explicit or implicit intent of engaging in sexual activity" (Jonason, Li, \& Cason, 2009, p. 460). I am requesting your participation, which will involve an interview regarding the initiation, maintenance, and termination of a booty call relationship. The interview should take between 30-60 minutes. To participate, you must be between the ages of 18 and 24 years old, and either currently be in or have had a booty call relationship.

Your participation in this study is voluntary. If you choose not to participate or to withdraw from the study at any time, there will be no penalty (it will not affect your relationship with Kayla Lucht, Dr. John Baldwin, or Illinois State University). Your responses are completely confidential. To ensure your confidentiality, we will not reveal any names, organizations, or anything else that identifies any participant.

We believe there are minimal perceived risks associated with participating in this project, though you may feel some discomfort discussing your experience with the booty call relationship. If you would like to see a professional to discuss any discomfort, you may, if you are a student at ISU, contact ISU Student Counseling Services at (309) 438-3655. If you are not an ISU student, you may, at your expense, contact a counselor of your choice. You will receive no compensation for this study. Your participation will help extend literature in sex communication, interpersonal communication, and script theory, providing valuable research for educational purposes.

Your signature below indicates that you are voluntarily making a decision to participate in this research study and have read and understood the 
information presented above. You will be given a copy of this consent form to keep.

Please direct any questions and/or comments to Dr. John Baldwin (jrbaldw@@ilstu.edu) or to me (kmlucht@ilstu.edu). For questions regarding your rights as a research participant you are encouraged to contact the Illinois State University Research Ethics and Compliance Office: Phone: 309-438-2529, Email: researchoffice@illinoisstate.edu

Thank you for your assistance.

Please Print Name

Please Sign Name

Date

Kayla M. Lucht

Graduate Student

Illinois State University

School of Communication

kmlucht@ilstu.edu 


\section{APPENDIX C \\ INTERVIEW GUIDE / QUESTION PROTOCOL}

\section{Demographic Questions}

1. Are you ready to begin?

2. How old are you?

3. What gender do you identify with?

Transition: Now I am going to start by asking some basic questions about booty call relationships.

\section{Basic Booty Call Relationship Questions}

1. How would you define a booty call relationship?

2. Where did you learn about booty call relationships?

a. Friends, media, etc.

3. What are your perceptions of booty call relationships?

4. How many booty call relationships have you engaged in?

Transition: Scripts are used to help individuals by giving them guidelines on how to act when entering a new or a specific situation. To date, there is no specific script on how booty call relationships are initiated between the partners. For these next questions, think about your most recent booty call relationship

\section{Booty Call Relationship Initiation}

1. How would you define your pre-existing relationship with your booty call partner 
2. Stranger, brief acquaintance, friend, etc Could you please tell me how the booty call relationship was developed?

a. Where did your partner first approach you?

3. What was said to influence you to engage in this booty call relationship?

4. Why did you decide to enter a booty call relationship?

a. Why did you decide to enter a booty call relationship with this specific person?

5. Were there any factors that influenced the initiation of this relationship?

a. Friends, alcohol, media, etc

b. How often did each factor influence the relationship

6. As the booty call relationship was developing, can you tell me about any emotions you were feeling due to this relationship?

a. What emotions do you think your partner was experiencing?

\section{Booty Call Relationship Maintenance}

1. Can you tell me how you maintained the relationship?

a. Where did you meet up for the sexual encounter?

i. Why at place?

b. Was there any specific time you would choose to meet up at?

i. Why that time?

c. Who would initiate the hookup?

i. How would they initiate a hookup:

2. Can you describe a normal conversation between you and your partner while trying to decide when to hookup?

a. Who would text whom first?

b. What would the text message say?

c. Would you discuss anything of importance?

d. How long would it take for the conversation to be about the booty call? 
e. How often would you guys text each other?

f. Were there any emoticons used?

3. Can you tell me about any ground rules that were established to maintain this relationship?

a. Why these rules?

b. How did these rules help the relationship?

c. How did these rules hurt the relationship?

4. How did you guys get into contact with each other?

a. Phone call, text message, social media

i. What was the primary way?

b. What did a typical text message look like

5. Once you arrived to the destination, would you greet your partner?

a. If so, what would you say? What would they say?

b. Would you hang out before engaging in sex?

i. If so, what were the activities?

ii. If not, why?

c. Would you hang out after engaging in sex?

i. If so, what were the activities?

ii. If not, why?

1. What would you do?

6. Would you self-disclose any information about yourself to your partner?

a. Vice Versa?

b. How long into the relationship was it before self-disclosure was communicated?

7. Were there any other factors that influenced each hookup?

8. What emotions did you experience while in this relationship?

a. What made you feel these emotions?

b. How do you think it helped the relationship?

c. How do you think it hurt the relationship? 
9. In your opinion, what emotions was your partner experiencing while in this relationship?

a. Did you explicitly talk about their emotions?

b. How do you think this helped the relationship?

c. How do you think this hurt the relationship?

10. Did you ever have multiple booty call relationships at once?

a. If so, why?

b. How did you keep these booty call relationships organized?

\section{Booty Call Relationship Termination}

1. How long did the booty call relationship last?

2. How often did you guys hook up

a. What days were the most common

3. In your opinion, why was this booty call relationship terminated?

4. Tell me about how it was terminated?

a. What was said specifically to end the relationship?

b. What channel was the termination message delivered?

i. Text, face-to-face, phone call, email, social media, etc.

c. If nothing was explicitly said, how did you know it was over?

5. Have you been in contact with your partner since the termination?

a. What type of channel?

b. Have you hooked up with your partner since the termination?

c. What factors influenced this re-hookup?

d. If not would you rehook up with your partner?

6. Can you please tell me about any emotions you experienced after the relationship was over?

a. What emotions do you believe your partner was experiencing due to the termination 
7. What would have you done differently?

8. Why did you not enter a traditional romantic relationship with your partner?

9. What would need to be done for you to want to enter a traditional romantic relationship with your partner? 